\title{
KAMBAL NA DISYERTO: ANG KOLONYAL NA KANON AT KOMERSYALISMO AT ANG PANIMULANG PAGPAPAAGOS NG MGA AGOS SA DISYERTO
}

\author{
Corazon Lalu-Santos \\ Kagawaran ng Filipino \\ Ateneo de Manila University
}

\section{Twin Deserts: Colonial Canon and Commercialism and the First Streams of Mga Agos sa Disyerto}

In tracing the beginnings of the overemphasis on canon in Filipino literature, Jose Garcia Villa is undoubtedly one of the first names that come to mind. To Filipino writers in English, he and his annual "Honor and Horror Lists" of poetry and short stories represented ideal standards to strive for. Inclusion in his annual selections was a legitimate seal of approval that signified one's entry into the canon, more than the numerous literary contests existing at the time. As Villa upheld Western standards in selecting what he considered the best of Filipino literature in English, he paved the way for a concept of canon that, according to critic Jonathan Chua, silenced the "Filipino" while highlighting "Literature" and weakened the dichotomies of American/Filipino, center/margin, civilized/savage, and colonizer/ colonized. It served as an opiate that blotted out the memory of Filipinos' "sour" acceptance of their American colonizers. Filipino writers were put at a disadvantage by Villa's canon, which placed the English language and Western standards at the center. Writers were confined to these western standards in the American colonial state. This was reinforced by the American curriculum, which positioned their "canon" as a major influence on Filipinos' literary tastes. As a result, the production of Tagalog literature was limited to commercial magazines.

By 1943, two decades after Villa's work, very little had changed. The rush toward a cosmopolitan American lifestyle drew attention away from a thorough understanding of the nation's experiences and created an obsession with making money. This was also the case for Filipino writers in Tagalog. Publication in commercial magazines brought income and popularity which, together with the colonial concept of canon, dried up the landscape of Tagalog literature, especially the Tagalog short story. Neither the contributions of wellknown writers such as Lope K. Santos, Valeriano Hernandez Pena, and Patricio Mariano, nor the publication of collections such as Clodualdo del Mundo's Parolang Ginto or Alejandro Abadilla's Talaang Bughaw - works that first challenged the existing culture of 
commercialism and its emphasis on income and popularity - could address this. The arrival of Japanese colonizers did not change these circumstances, either, as writers during this period were motivated mainly by the need to survive in those tight times. The formulaic writing (entertainment and didacticism) of Tagalog writers for Liwayway magazine thrived under the management of Agustin C. Fabian. Readers' patronage of this style of writing kept the magazine afloat and ensured its success.

It is in this context, with the English language laying the foundation for Western standards and commercialized creation, that young writers such as Rogelio Sikat, Efren Abueg, Edgardo M. Reyes, Eduardo B. Reyes, Rogelio Ordonez, and Dominador Mirasol would create new streams for what they considered the "desert" of the Tagalog short story. All former writers for commercial magazines, these young men, the "New Blood", found a venue for fighting against western canon and commercialism in The Quezonian, the campus publication of Manuel L. Quezon University. The same education used by the colonizers to blind the people was used by the young writers to create streams that flowed into the desert like state of the Tagalog short story thus the term "Agos" was conceived. Exposure to the works of Hemingway and other writers opened the doors for creating stories that went beyond overused themes, erratic points of view, and idealization of subjects. Their stories expressed their opposition to the status quo and led to the publication of the 1965 anthology Mga Agos sa Disyerto, which revealed the new standards of these young writers. Mga Agos sa Disyerto formally declared a new direction for the Tagalog short story and would be recognized by critics as a pioneer, a herald of a new way of looking at the world, of turning a critical eye toward established traditions, with the intention of changing the way of life.

\section{Keywords}

Agos sa Disyerto, Colonial Canon, Colonial Education, Commercial Literature, Anthology

\section{About the Author}

Corazon Lalu-Santos is an Associate Professor in the Department of Filipino, Ateneo de Manila University and currently the Chair of the Technical Committee for Filipino of the Commission on Higher Education (CHED). She completed her Ph. D. in Filipino Literature at the University of the Philippines, Diliman. She was former Chair of the Department of Filipino at the Ateneo de Manila University, former secretary and now executive committee member of the National Committee for Language and Translation of the National Commission for Culture and the Arts (NCAA). She was also a three-term president of Sanggunian sa Filipino, a national organization of Filipino Departments in the Philippines.

She has written creative and critical articles published in Diliman Review, Heights, Ad Veritatem, Pelikula Magazine and Sangfil Sourcebook. She was co-editor of TilamsikDiwa, an anthology of poems of writer-politician Socrates Rodrigo, and Coordinator of textbooks in Filipino language and literature for high school such as Kawil and Sambotani. She has also lectured on literary criticism, Filipino language and on topics in education such as the new K-12 educational system being implemented in the Philippines. 
The expert in matters of taste is in awkward position when he differs from the majority. He is forced to say in effect, "I'm better than you. My taste is more refined, my nature more cultured, you will do well to become more like me than you are.

-Jose Garcia Villa 
MAHIRAP UMANO ANG KINALALAGYAN NG MGA EKSPERTO o kritiko lalo pa't naiiba ang kanilang tingin sa tanaw ng nakararami. Kailangan nilang paniwalaan ang sarili bilang nakauungos sa iba. Matatagpuan sa paniniwalang ito na nagiging mainam lamang ang iba pagkaraang makaangkop ng mga ito sa eksperto-iyan ang rurok ng matayog na tingin ni Jose Garcia Villa, ang kritikong lalong pinasikat ng kanyang "Honor and Horror Lists" sa tula at maikling kuwentong Ingles. Ngunit higit pa rito ang epekto ng proyektong Villa, kung tutuntuning ito ang magtuturo ng kamalayang maka-kanon ng maraming manunulat sa Ingles at Pilipino. Magiging matayog/mataas lamang ang pagtingin ng mga manunulat sa kanilang sarili kung nakaabot o napapabilang ang kanilang akda sa tinatawag na kanon. ${ }^{1}$ Para sa sino mang manunulat, isa itong lehitimong tanda ng kanyang kahusayan. Higit pa ito sa karangalang inaabangan ng mga premyado na at baguhang manunulat mula sa iba't ibang paligsahang pampanitikan. ${ }^{2}$ Sa kasaysayan ng panitikang Tagalog (P/Filipino) hindi ito madaling marating lalo pa't dominante ang panitikang nasusulat sa Ingles ng mga manunulat na Pilipino at ng mga kritikong humabi ng pamantayang hango sa kanluran. Ang personal na tala ng pinakamahuhusay na akda ni Villa (noong una ay maikling kuwento at nang lumaon ay tula) ay nagpasimula ng ayon kay Jonathan Chua ng pagpapatahimik sa "Pilipino" at pagpapatatag sa kung ano ang "panitikan." Idinagdag pa ng kritiko na ito rin ang nagdestabilisa sa mga dikotomiyang tulad ng "Amerikano/Pilipino", "sentro/laylayan", "kolonisador/kolonya", "Silangan/Kanluran", sibilisado/barbaro, "rasyunal/irasyunal", at "progreso/kawalang-progreso" ${ }^{3}$ Para kay Chua, ang naging kapangyarihan ni Villa sa kritisimong pampanitikan ang naglusaw sa mga dikotomiyang dapat ay sinusuri. Maraming manunulat ang naghangad na "mapabilang" sa "kanon" ni Villa. Pagkaraan ng dalawang dekada mula noong inilabas niya ang una niyang "Honor List" at "Horror List" noong 1927 sa The Philippines Herald, pagdating ng dekada singkuwenta, naging lubhang mahalaga na si Villa. Ang inaantabayanang listahang ito ay hindi namamalayang halos naging katumbas ng pagkaluklok sa "kanon". Nagkumahog ang mga manunulat lalo na iyong mga naging "kapanalig" sa pagtugon sa pamantayang ayon kay Villa ay unibersal. ${ }^{4}$ Idinagdag pa ni Chua na maging si Epifanio San Juan ay isa sa marami nang nagsabi na naisakatuparan din ni Villa ang proyekto ng maluwag na pagtanggap sa kolonisasyong Amerikano gamit ang panitikan at ang kanyang pamantayang-Villa, kaugnay ng usaping pambansa. ${ }^{5}$ Magbubunga ito ng matinding sugat sa mga manunulat na Pilipinong sumusulat o gumagamit ng Tagalog sapagkat babanggit si Villa ng mga sangkap bilang panukat sa mabuting panitikan na hayagang nakamodelo sa kanluran. Lalo pang magiging matindi ang sugat ng mga manunulat sa Tagalog/Pilipino sa espasyong ilalaan sa mga produksyong Tagalogang mga komersyal na magasin, habang dinarakila na ang mga akdang tumutupad sa pamantayang hango sa mga Amerikano at kinakalinga ng akademya 


\section{Ang Maikling Kuwentong Tagalog at ang mga Pagsisikap sa Pagbuo ng Sukat-Ikarangal na mga Akda sa Gitna ng Usapin ng Kolonyal na Kanon}

Isinilang ang mga kuwentong Agos sa panahong kinailangan nilang makipaggitgitan upang mahawan na muli ang landas tungo sa paglikha ng maituturing na "panitikan". "Muli", sapagkat kung tutuntunin ang kasaysayan ng pagsisimula ng maikling kuwentong Tagalog (F/Pilipino), ang kanilang naging hakbang ay iginiit ding maganap ng mga noo'y kagaya nilang kabataang manunulat na humihingi ng paglaganap ng mga mabuting akdang Pilipino. Mula sa simula ng kasaysayan ng uring ito, taong 1943 na ay hindi pa ganap na maituring ng pangunahing kritikong Teodoro A. Agoncillo ang kabulasan nito gayong dalawang dekada na ang lumipas mula sa pagkausbong nito bilang kuwento na mauugat naman sa tinawag na instantanea. ${ }^{6}$ Ayon kay Agoncillo:

Ang sangay na ito ng panulatan ay hindi pa maituturing na nasa karurukan na at kaipala'y dumating na sa kanyang takdang gulang, sapagkat ang mahuhusay na mangangatha ng uring iyan na babasahin ay pawang batang-bata pa at hindi pa nagkakaroon ng mabubulas na karanasang dulot ng mahabang taon ng pagmamatyag, pag-aaral at pakikipamuhay sa lipunang kinaaniban ng lahat. [akin ang pagdidiin] ${ }^{7}$

Hindi nakita ni Agoncillo sa maikling kuwento sa kanyang panahon ang tatlong ito: pagmamatyag, pag-aaral at pakikipamuhay sa lipunang kinaaniban ng lahat sapagkat kung tutuntunin, may mahabang kasaysayan ng pagkahirati sa paglikha ng kita at popularidad kaysa sa panitikan ang noo'y matatandang manunulat. Malaki ang kaugnayan ng panahon na kanilang kinabibilangan sa ganoong uri ng produksyon. Panahon ito ng kolonisasyong Amerikano na bukod sa nagbukas sa kalayaan sa pamamahayag, ay higit na nagawang katakam-takam sa mga Pilipino ang kosmopolitanong buhay. Hinabol ng mga Pilipino na makapamuhay gaya ng uri ng pamumuhay-Amerikano. Nagbunsod din ito ng materyalismo. Ang maskara ng pag-unlad kasama ang natatanging "taktika" ng pagpapatahimik ng mga polisiyang tulad ng benevolent assimilation at Filipinization of the bureaucracy ng Amerika ay nagpasigla nga sa paglikha subalit marami sa mga ito ay likha upang ipakilala ang pagbabagong-ayos ng kabuhayang panlipunan. Bagamat mayroon pa ring tumutuligsa rito tulad ng mga naisulat na dagli ni Lope K. Santos na "Sumpain nawa ang mga Ngiping Ginto" at "Bagong Hudas" ni Rosauro Almario, kapwa nalathala sa pahayagang Muling Pagsilang. Nagumon ang mga manunulat sa panahong ito sa pagsulat ng mga pangaral, karanasan sa pag-ibig at ng mga tinawag ni Agoncillo na pasingaw. ${ }^{7}$ Maidaragdag na may kaugnayan ang pamumutiktik ng mga instantanea sa prosa romantica noong 1900's gaya ng "Redencion", "El Suegro de Kokumura" at "Pais de Ensueno" sa naging direksyon ng mga dagli ${ }^{8}$ na nang lumaon ay nakabuo ng 
gayong oryentasyon sa manunulat at maging sa mambabasang Pilipino. Lumikha ng di gayong ganansiya iyon sa mga manunulat sapagkat nagagawa nila ang kanilang nais - nangangaral habang kumikita at umaani ng popularidad. Ganito pa man, kinilala ni Agoncillo ang mga pangalang Valeriano Hernandez Pena, Patricio Mariano, Lope K. Santos bilang mga naghawan ng kasaysayan ng maikling kuwentong Tagalog Ngunit, itinakda niyang hanggang doon lamang ang kanilang kontribusyon. Ani Agoncillo:

Hindi na dapat pang lapatan ng sukatang pampanitikan ang kanilang mga akda-tiyak na hindi maaaring lumampas, sapagkat walang pag-aalinlangang hindi pa nila nababatid ang tunay na katuturan ng taal na maikling katha... ${ }^{10}$

Pinabangon mula sa gayong kalakaran ang maikling kuwentong Tagalog ng patimpalak-panitik na binuksan ng pahayagang Mithi noong 1910. Inihalal ng mga mambabasa ang "Elias" ni Rosauro Almario na nagkamit ng unang gantimpala. Ito ang hudyat para kay Agoncillo ng pamumulaklak ng maikling kuwentong Tagalog. Naging bahagi ang mga pahayagang Taliba, Ang Democracia at Mithi sa pag-unlad ng uring ito. Nagluwal din ang buwanang patimpalak ng Mithi ng mga akdang ayon kay Agoncillo ay nakauungos na ang uri. ${ }^{11}$ Samantalang napakarami ng dagli na pumaksa sa pag-ibig, mayroon ding lumandas sa tradisyon ng makabansang panitikan ng Propaganda at Himagsikan na makikita sa mga akdang "Kaalakbay sa Daan" ni Gonzalo Malay, "Luha ng Alipin" at "Estrangheritis" ni Inigo Ed Regalado, at "Sa Diwa at Pag-ibig" ni Antero Gempesaw. Napasimulan na rin bago pa tumapak ang taong 1920 ang mga akdang pumaksa sa suliraning agraryo at manggagawa. Matatagpuan ito sa "Buhay at Kalayaan" ni Fidel Francisco Laksamana, "Napakatunggak Ako" ni Liling at "Puring" ni Patricio del Rosario. ${ }^{12}$

Sa pagkatatag ng lingguhang Liwayway noong 1920, lalong sumigla ang pagsulat ng maikling kuwento ngunit, patitingkarin pa ito ni Clodualdo del Mundo sa pagpasok ng taong 1927 kung kailan niya pinasimulan ang kanyang talaan ng Parolang Ginto. Naging masidhi ang hangarin ng mga kuwentista sa mga pahayagan at magasin na pagandahin ang kanilang likha upang magkaroon ng karangalang ihahatid ng talaang iyon ni del Mundo. ${ }^{13}$ Magiging kaagaw ni del Mundo sa gawaing ito si Alejandro Abadilla na naglabas naman ng Talaang Bughaw noong 1932. Ipinagpatuloy ang pamimiling ito nina del Mundo at Abadilla ng mga kapisanang Kalipunan ng Kuwentista at Ilaw at Panitik. Hatid ng mga pamimiling iyon ang wari ay pag-angat ng uri ng mga naisulat na kuwento ayon na rin sa pansin ni Agoncillo:

Sumulpot kapagdaka, gaya ng dapat asahan, ang isang uri ng manunulat na nalahiran nina Poe, de Maupassant, O. Henry, Anderson at Saroyan. ${ }^{14}$ 
Nagkaroon ng pagsasanib puwersa sina del Mundo at Abadilla na nakitang dapat pagbuklurin ang mga manunulat na nakatapos na o kasalukuyan pang nasa unibersidad. Sa ikalawang pulong, nabuo ang kapisanang Panitikan na itinuring na sakdalista at aristokrata ${ }^{15}$ na kumuwestiyon sa monopolyo ng matatandang manunulat na malaki ang espasyo sa mga lingguhang magasin. Humingi ang grupo ng Panitikan—na hindi lamang kinabibilangan nina Abadilla at del Mundo, bagkus kasama rin sina Salvador Barros, at Teodoro Agoncillo-ng dagdag na puwang, para sa kanila na umabot pa sa sa paghikayat ng sa mga mambabasa na iboykot ang mga babasahin. Mula sa sagutan, naging mapusok ang bawat panig kung kaya sa pagtatagpo nila ay laging may pisikal halos na pagsasabong na nagaganap. ${ }^{16}$ Naging rurok na pangyayari ang pagsusunog ng mga akdang hindi dapat ikinararangal kapwa ng matatanda at kabataang manunulat sa Liwasang Moriones ng Tondo noong ika2 ng Marso 1940; iginigiit ng mga kabataan ang pagbabanyuhay na ayon sa kanila ay dapat nang danasin ng panitikang Tagalog_ang pagbabago sa pamamaraan ng pagkukuwento. Dahil aral sa mga unibersidad ang grupo ng mga kabataang ito ay hindi rin nakaiwas sa paggamit sa mga kuwento ng mga banyagang manunulat gaya nina Parker, Hemingway at Saroyan bilang mga modelo. Ganito pa man, ito ang maituturing na unang bugso ng mga kabataang manunulat na humamon sa kalakarang kanilang dinatnan na nakakulong pa sa panahong ang panitikan ay walang iba kundi pagpapaubaya sa popularidad, komersiyo at matandang kalakaran/pamantayan. Nakatali din ito sa tradisyonal na mga sangkap tulad ng de-kahong paggamit ng wika, lantarang pangangaral at malabis na pagbubuhos ng damdamin. Nag-ibayo ang kanilang hangaring iangat ang panitikang Tagalog na lalo nang naganap sa tula at maikling kuwento sa pagkabuo rin ng Ilaw ng Bayan na pinasimulan ni Antonio B.L. Rosales noong 1937. Sa panahong ito, lumawak na rin ang impluwensya ng organisasyong Panitikan at Ilaw ng Bayan, na higit na binigyang diin ang paglayo ng panitikang Tagalog sa komersyalismong ugat ng produksyong pampanitikang lalong nakatali sa mga lumang sangkap ng tradisyonal na kuwento. Nakarating na rin ang maikling kuwentong Tagalog sa pagtatatag ng malilinaw na pamantayan ng itinuturing na mainam na kuwento. ${ }^{17}$ At habang sinisikap ng mga kuwentistang Tagalog at mga kritiko ang tuluyang paglayo sa dating kalakaran ng mga panahong iyon, si Jose Garcia Villa naman ay nagpatuloy sa proyekto niya ng "kanon", sa pagluluklok sa mga manunulat na eksklusibong mapapabilang sa "Roll of Honor" niya at nagpakilala na ng higit na matatag o estabilisadong kalagayan ng maikling kuwento sa Ingles. Kung kaya walang pangingimi niyang sasabihin:

I reaffirm this year my faith and pride in the Philippine short story. Though but a decade old, the art, in the Philippines, has thrived to such degree of artistic cultivation so that it is today-all the other arts considered--- the most important Philippine art. Already we have produced, during this initial period, a remarkable, a truly remarkable body of short fiction: this comprise a group of approximately 120 stories whose value as literature is permanent. ${ }^{18}$ 


\section{Ang Kanon at Komersyalismo: Disyerto ng Maikling Kuwentong Tagalog}

Wari isang bumabalik na multo ng manunulat ng maikling kuwentong Tagalog ang pagkarahuyo sa materyal na ganansyang ihahatid ng kanilang panulat. Isang matandang sakit pamula pa noong panahon ng dagli na tangi nilang hinahabol ay kita at popularidad. Lalo pa itong nabibigyang-katwiran kung may kondisyong sapat na dahilan upang makalimutan ang mga pagsisikap sa paggigiit sa karangalan sana ng mga manunulat sa Tagalog.

Doon sila ihahatid sa magiging mahirap na buhay sa pagpasok ng kolonisasyon ng Hapon upang sandaling maputol ang mga napasimulan sa maikling kuwentong Tagalog sapagkat ipinasara ng mga Hapon ang lahat ng pahayagan at magasin. Ang Liwayway lamang ang papayagang muling buksan at dahil sa dalawa lamang ang mapaglalathalaan ng mga manunulat sa Ingles-ang Philippine Review at Tribunenakisiksik rin sila sa Liwayway at nagsulat sa Tagalog. Sa praktikal na dahilang magkaroon ng, ayon nga kay Agoncillo ay "kapeng-mais at gatas-na-gatang may bantong tubig," nakisali sa dagsang pasulatan ang mga dating nagsusulat sa Ingles. Matutuntong dito, muling nabuhay ang pagkawala ng mga mabuting kuwento. Subalit sa kapangyarihan ng patnugot ng nag-iisang Liwayway noon, may mangilanngilang kuwentong natatangi na kasama ng mga "nanlalapot at nanlalagkit". ${ }^{19}$ Maniobra ng gobyernong Hapon ang maituturing na pagdagsa ng panitikang Tagalog sa panahong iyon dahil ipinawawaksi nito ang mga tatak na Amerikano sa mga Pilipino. Subalit hindi rin ito maituturing na pangyayaring masasabing ganap na nagpataas sa kalagayan ng panitikang Tagalog sapagkat ginamit lamang ito ng maraming manunulat upang makakain sa panahong iyon. Ganito pa man, mahalagang pansinin na lumayo sa lunsod-kosmopolitanong pamumuhay, isang kamalayang iniuugnay sa buhay-Amerikano, ang paksa ng mga kuwento nina Brigido Batungbakal, Macario Pineda, at Narciso Reyes na tumuon sa timyas ng buhay sa lalawigan. Inihudyat ng paglabas ng 25 Pinakamahuhusay na Kathang Pilipino $n g 1943$ ang muling pagkabuhay ng pagsulat na nagsasaalang-alang sa malilinaw na pamantayan, partikular na sa maikling kuwentong Tagalog. Subalit bago pa tuluyang dumating ang dekada singkuwenta, lalamunin muli ng kumunoy ng komersyalismo ang paglikha ng mga manunulat sa pagdagsa ng mga magasing Saga-Saga, Pag-asa, Sinag-tala, Bulaklak, dagdag pa sa noo'y naghaharing Liwayway ay pawang nagsisipag-agawan sila sa mga mambabasa upang maipabasa ang wari ay pabrika ng mga likha na "hindi masinagan ng kahit na gahanip na katunayan sa buhay, ng tunay na kakayahan ng manunulat, ng matayog na kaisipan, at ng matinding damdamin.." ${ }^{20}$

Sa takbo ng kasaysayan ng maikling kuwentong Tagalog, nagpapaulit-ulit ang pangyayaring nababalaho ang pag-usad ng uring ito sa paglikha ng wika nga ay di-ikinararangal na akda. Nariyan ang suliraning pangkabuhayang laging isinasaalang-alang ng mga palathalaan na siya namang gumigipit sa mga manunulat 
at nagtutulak sa kanila upang lumikha ng produksiyong iyong "hinihingi" lamang ng mga mambabasa. Dulot nito, hindi sila tuluyang makahulagpos sa matandang pormula ng pagsulat na itinakda ng mga nakatatandang manunulat (na sila pa ring hinahanap-hanap sa magasin) noon sa maikling kuwento sa Pilipino. Disyerto ang lilikhain ng pagkagumon sa kita ng mga nagsusulat sa Pilipino. Maitutumbas ang paghahabol sa "kitang" ito sa komersyalismo sa paglikha. Itinuturing na isang katotohanan ni Agustin C. Fabian na noo'y kabilang sa hanay ng "makabagong" manunulat, ang halaga ng kita (komersiyo) sa buhay ng mga manunulat sa Tagalog/ Pilipino. Lumilitaw na ito ang natuklasan at napatunayan niya sa matagal niyang pagiging kagawad at patnugot ng Liwayway. Ang ganitong ugnayan ng komersiyo at paglikha ay mahirap noon na isantabi. Ayon nga kay A. C. Fabian:

Dapat malaman ng mga sumusulat ng kuwento at nobela na hindi maiiwasan ng isang patnugutan na kilingan ang mga awtor na may pangalan na at may libu-libong mambabasang sumusubaybay. Sapagkat nasa dami ng mambabasa ang ilalawig ng buhay ng alinmang peryodiko, maging lingguhan, pang-arawaraw o buwanan. At ang dami ng mambabasa ang magpapasya kung kikita o malulugi ang isang peryodiko. At kailangan ng isang peryodiko na kumita ng sapat upang mabawi ang puhunan sa makinarya, sa papel at tinta, upang may ipasahod sa bumubuo ng patnugutan, upang mabayaran ang mga akdang nalathala. Ang lahat ay nakasalalay sa dami ng mga mambabasa. ${ }^{21}$

Lalong mapapatingkad ang pagkatigang ng maikling kuwentong Pilipino dahil sa mga panahong iyon hindi na maikakaila ang luklukan ng mga maikling kuwento sa Ingles (o alinmang uri ng panitikang nakasulat sa Ingles) bilang ang nasa "bahay", kumpara sa "silong" na kinalalagyan ng panitikang Tagalog. Dekada trenta pa lamang ay idineklara na ni A.V. Hartendorp na mahinang klase (inferior) ang mga ito sa mga akdang nakasulat sa Ingles. ${ }^{22}$ Dahil din ito sa pagpapalagay na ang panitikang Tagalog ay sentimental, didaktiko, at patuloy na sumasandig sa pormularyong paglikha. ${ }^{23}$ Bagaman "butas ng karayom" ang dinaanan ng kontrobersyal na modelo ng modernong panitikan na itinaguyod ni Jose Garcia Villa noong dekada trenta na hindi niya tinalikuran (consistent siya sa paggigiit ng kanyang pamantayan), dalawang dekada pagkaraan ay aanihin niya ang tagumpay at ipuputong ang lawrel sa kanya bilang pinapanginoong manunulat at kritiko ng modernong panitikan sa Ingles. Inangkin ni Villa pagkaraan ang lisensya sa pagbuo ng aprobadong listahan ng mabuting kuwentong nasa Ingles sa bawat taon.

Higit na masuwerte ang panitikang nasa Ingles sa pagdating sa ganoong antas sapagkat kinandili naman sila sa simula pa lamang ng estadong Amerikano. Nangyari mang nanghina sila at nakisiksik pa ang ilan sa paglipat sa Tagalog sa panahon ng Hapon, kaagad silang nagkabuhay na muli sa higit na dumaming ng palathalaang nagbukas para sa kanila-ilan sa mga ito ang Philippines Herald Magazine, Graphic at Sunday Times Magazine-pagkaraang mabawi ng Amerika 
ang Pilipinas sa kamay ng mga Hapones. At habang nasa ganoong antas ang panitikang Ingles, pinangalagaan ng mga magasin ang komersiyo na kumontrol sa uri ng produksiyon ng panitikang Tagalog (Pilipino), popular at naghahatid ng aliw sa mambabasang Pilipino. Ito ang malinaw na pagpapatibay sa ipinahayag ni A.C. Fabian ukol sa ugnayan ng paglikha at komersiyo ng mga nagsusulat sa Pilipino.

Subalit kailangang kilalanin na sa kasaysayan ng maikling kuwentong Tagalog naisilang din ang mga indibidwal na tagasuri at nagtaguyod ng kanilang "kanon"ang tanda ng pagsisikap upang labanan ang disyerto. Malalagom ito sa sumusunod:

1. Ang Parolang Ginto ni Clodualdo del Mundo noong 1927 na nagsimula sa pamimili ng sa palagay niya'y pinakamahuhusay na katha ng mga buwan at taon. Tumagal ang panunuri't pamimiling ito hanggang 1935. Kabilang sa mga binigyan ng karangalan ng Tao sa Parolang Ginto at kinilalang mga katha ng taon ang sumusunod:

1927- "Paghahangad" ni Arsenio R. Afan

1928-"Hiwaga" ni Arsenio R. Afan

1929-"Lihim ng Kumbento" ni Juan Rivera Lazaro

1930-"Panata ni Pilar" ni Amado V. Hernandez

1931-"Sugat ng Alaala" ni Fausto J. Galauran

1932-"Walang Lunas" ni Amado V. Hernandez

1933-"Manika ni Takeo" ni Deogracias A. Rosario

1934-"Ang Dalagang Matanda" ni Deogracias A. Rosario

1935-“Ay! Ay!" ni Rosalia L. Aguinaldo

2. Ang Talaang Bughaw ni Alejandro G. Abadilla ay sinimulan niya noong 1932. Isa rin itong taunang pamimili sa buwanan at taunang pinakamahuhusay na akda, tula man o katha. Nagbigay ito ng higit na diin sa tumpak na pamamaraan o kaanyuan kaysa sa nilalaman ng akda. Kabilang sa mga binigyan niya ng karangalan at kinikilalang katha ng taon ang sumusunod:

1932 - "Aloha" ni Deogracias A. Rosario

1933-"Ako'y Mayroong Isang Ibon" ni Deogracias A. Rosario

1934-"Pusong Uhaw sa Pag-ibig" ni Inigo Ed Regalado

1935-"Pag-ibig na Walang Kanluran” ni Alberto Segismundo Cruz

3. Ang 50 Kuwentong Ginto ng 50 Batikang Kuwentista ni Pedrito Reyes ay nalimbag noong 1939. Kaiba sa naging proyekto nina del Mundo at Abadilla, inamin ni Reyes na wala siyang ginamit na tiyak na panukat sa pagbuo ng inaakala niyang mapapabilang sa kanon ng mabubuting kuwentong Tagalog. Aniya, hinayaan niyang magpasya ang mga manunulat rito at ipagkaloob sa kanila ang sa tingin nila'y pinakamabuti nilang naisulat na kuwento. 
4. Ang Kalahating Siglo sa Talambuhayng Kamalayan: Ang 25 Pinakamabuting MaiklingKathangPilipino ng 1943. Isang tanging Lupong Tagasuri ang nilikha ng Manila Sinbun-sya (pahayagang Hapon) at isang Lupon ng Pamahalaan na nilikha ng Republika ng Pilipinas sa pamamagitan ng Kagawarang-Bansa sa Pagtuturo ang nagtuwang noong ika-25 ng Marso 1943 upang mabuo ito. Ayon sa paliwanag sa panimula ng aklat, dumaan ito sa masinsinang pagbasa, mayroong ginamit na pamantayang panukat upang mapabilang sa listahan at binubuo ng mga pinagpipitaganang kuwentista ang lupong nagsuri (Jose Esperanza Cruz, Agustin C. Fabian, Arsenio R. Afan, Antonio B. L. Rosales, Clodualdo del Mundo, Francisco B. Icasiano, Buenaventura G. Medina at Teodorico C. Santos), Ang sumusunod na kuwento ang napabilang sa aklat:

"Lupang Tinubuan" ni Narciso Reyes

"Uhaw ang Tigang na Lupa" ni Liwayway Arceo

"Lunsod, Nayon, at Dagat-Dagatan" ni N.V.M. Gonzales

"Suyuan sa Tubigan" ni Macario Pineda

"May Umaga Pang Daratal” ni Serafin Guiniguindo

"Sumisikat Pa ang Araw" ni Gemiliano Pineda

"Paghihintay" ni Emiliano Aguilar Cruz

"Dugo at Utak" ni Cornelio Reyes

“Mga Yabag na Papalayo" ni Lucilla Castro

"Tabak at Sampagita" ni Pilar Pablo

"Madilim Pa ang Umaga" ni Teodoro Agoncillo

"Ikaw, Siya, at Ako" ni Brigido Batungbakal

"Kadakilaan: Sa Tugatog ng Bundok" ni Brigido Batungbakal

"May Uling sa Bukana" ni Teo S. Buhain

"Bansot" ni Aurora Cruz

"Bahay sa Dilim" ni Alfredo Enriquez

“Tao, Ang Kahoy, at ang Bagyo" ni Aristeo Florido

"Nagmamadali ang Maynila" ni Serafin Guinigundo

"Si Ingkong Gaton at ang Kanyang Kalakian" ni Serafin Guinigundo

"Unang Pamumulaklak" ni Hernando Ocampo

"Mga Bisig" ni Amado Pagsanghan

"Sinag sa Dakong Silangan" ni Macario Pineda

"Mga Diyos" ni Justiniano del Rosario

"Luad" ni Gloria Villaraza

Mamalas din sa kasaysayang ito ang pagsisikap na mailugar at mapatatag ang maikling kuwentong Tagalog subalit may makatotohanang kondisyon din ang mga manunulat sa Tagalog (F/Pilipino) noon na hindi maitutulad sa higit na mabuting kapalaran ng mga nagsusulat sa Ingles. Sa kanilang henerasyon samakatwid, may 
relasyon ng komersiyo at panitikan na hindi ganoon lamang maisasantabi-walang espasyo sa magasing popular ang produksiyong walang "appeal" sa tagatangkilik ng mga naturang magasin. Ngunit kaalinsabay noon ay ang pangangailangang kumayod at mabuhay ng mga manunulat sa Tagalog. Sa ganitong konteksto, apat lamang ang malilimbag na antolohiya, sampung taon bago isilang ang Mga Agos sa Disyerto. Itong mga antolohiyang ito ang maglalabas ng listahan ng mahuhusay na akda at manunulat o ang kanon ng maikling kuwentong Tagalog (F/Pilipino). Ito ang sumusunod: Ako'y Isang Tinig ni Genoveva Edroza Matute, limbag noong 1952; Ang Maikling Kathang Tagalog na pinamatnugutan nina Alejandro G. Abadilla, F.B. Sebastian, at A.D.G Mariano, nilimbag noong 1954; Maiikling Katha ng 20 Pangunahing Awtor nina Alejandro G. Abadilla at Ponciano B.P. Pineda na nalimbag naman noong 1952; at ang Carlos Palanca Memorial Awards for Literature, English and Tagalog Prize-Winning Stories, 1950-1955 ni Kerima Polotan noong 1957. Kung isasaalang-alang ang kanipisan ng produksiyon sa pag-aantolohiya upang maipalaganap ang kanon ng maikling kuwentong Tagalog sa panahong iyon, mahahayag ang tagumpay ng operasyon ng "pamantayang unibersal" na naging sangkalan ng mga manunulat sa Ingles. Hindi makakapagprodyus ng mainam na akda ang kinomersyong paglikha na naging kaabalahan ng manunulat sa Pilipino noon. Maging si Rogelio Sikat ay umamin sa ungos ng panitikang Ingles kaysa sa Pilipino noong panahong iyon. Aniya:

Maunlad ang panitikan sa Ingles sapagkat mayaman at maunlad ang natitipong panitikang Ingles.. Wala pang mayamang panitikang sarili na mapaghahanguan; kailangang sa Ingles pa siya humango ng kaalaman at kakinisan; kailangan pang ang natutuhan niyang ito sa panitikang Ingles ay buong ingat niyang ilapat sa pagsusulat sa Tagalog... ${ }^{24}$

Subalit higit pa rito ang epektong ihahatid ng "praktis pampanitikan" (literary practice) ng mga nagsulat sa mga komersyalisadong magasin. Kung sisipatin, nagbunga ito ng disyerto at marhinalisasyon sa mga manunulat sa Pilipino. Aparatong ideolohikal ang kondisyon ng komersyalismo at ang proyekto ng pamantayang unibersal ng mga Amerikano upang tanggapin na mahina ang panitikang Pilipino kaysa sa Ingles. Kay Althusser, ganoon nakahuhubog ng kongkretong indibidwal na subheto ang ideolohiya. ${ }^{25}$ Subalit bakit nga ba kailangang igiit ng mga manunulat sa Pilipino ang pagbuo ng kanon? Ayon kay Isabel Pefianco, itong kanon ang ganap na nagsakongkreto ng proyekto ng kolonisasyong Amerikano na nakapaloob naman sa edukasyon. ${ }^{26}$ Ideolohikal na aparato ng estado (ISA ni Althusser) ang edukasyong ito na ginamit ng mga Amerikano sa pagtuturo ng pagbabagong kultural sa mga Pilipino. Sa tinalunton ni Pefianco, ipinakita niya kung papaanong nag-eksperimento ang mga kolonisador na Amerikano sa paghubog ng kanon na magagamit upang maganap ang instruksiyon sa wika at pagbasa sa primarya at sekundarya, na isusubo para sa mga mag-aaral na ito noong unang dekada 
ng kolonisasyong Amerikano. Ang mga unang ginawa nila ayon pa kay Pefianco ay disaster na maituturing, lalo't higit ang paggamit ng listahan ng mga akdang pampanitikang ganap na banyaga sa mga Pilipino sa mga angkat na teksbuk sa Amerika. ${ }^{27}$ Subalit hindi dito titigil ang mga Amerikano dahil hanggang 1910 nagpapabagu-bago ang kanilang listahan ng akdang kanilang ipinababasa ngunit, pare-pareho at pawang mga tekstong Ingles lamang ang mga ito.

Taong 1934 nang itinatag ng pamahalaang Amerikano ang komite na namahala para matugunan ang pangangailangan sa materyales. ${ }^{28}$ Ngunit bago ito nagpanukala ng mga akdang mapapabilang sa dapat mabasa ng mga mag-aaral, naghanay ito ng anim na tuntuning dalawa lamang dito ay patungkol sa anumang Pilipino para kay Pefianco. ${ }^{29}$ Dagdag pa niya, ang natitirang apat ay mga tuntuning nagtago sa pagpapakita ng tanggap at tama para sa lahat (nakabatay sa unibersal na katotohanan), ${ }^{30}$ hindi lamang para sa sarili. Sa panahong kontrolado ng mga Amerikano ang sistema ng edukasyon sa Pilipinas sa loob ng apat na dekada at sa gitna ng nagpapalit-palit na listahan ng kanon ng mga babasahing Ingles, makikitang naging malinaw na behikulo ang edukasyon sa pagtataguyod ng kolonyal na kanon. Hindi kailan man makakapasok sa kanong ito nang gayon lamang ang mga akdang isinulat ng mga Pilipino kahit ng nagsusulat noon sa Ingles, ngunit lalo namang walang espasyo rito ang mga nagsusulat sa Pilipino dahil malinaw itong pagtanggi sa "paggagad" upang maging Amerikano (magbubunga ito ng pagka-Amerikano sa lahat ng aspekto at gawi ng buhay ng dating Pilipino). Kung bubuuin samakatwid ang senaryo, sa sekundarya at primaryang edukasyon at sa unibersidad, kanong Ingles ang namamayani. Kaya nga, mayroon mang akdang isinulat ng Pilipino noon na binabasa, dahil iyon sa "gagad" lamang ito ng panitikang Amerikano-mga walang ipinagkaiba sa ginagaya. Kung gayon, matapang na pahayag ang napasimulan nina Del Mundo, Abadilla at ng lupon nina Esperanza Cruz dahil sa gayong uri ng laban ng pananakop sa isipan (sa pamamagitan ng edukasyon at kanon) ng bayan, ang kanon na nilikha nila ay pangkontra-kamalayang ipinalalaganap ng kolonisador na Amerikano. Ngunit may realidad silang kinailangang harapin-una, ang antolohiyang binuo nila sa kanilang panahon noon na hindi pa hahalili sa mga babasahing Ingles na kailangan/kahingian (must and required) sa mga magaaral; at pangalawa, ang popularidad din noon ng mga komersyal na magasin na higit na nakilala bilang espasyo ng mga manunulat sa Pilipino at itinuring bilang mababang uri sa paglulunoy nito sa romantisismo, aliw at pantasya. ${ }^{31}$ Iyon nga ang produksyong magkukubli sa realidad na dapat makita ng mga mambabasa. Sa dagdag na teoriya ni Pefianco, kung gayon, hindi lang nagdulot ng pagpapabansot sa kaisipang Pilipino ang mga tekstong nakasulat sa Pilipino ang mga kolonisador na Amerikano; nabansot din ang kaisipan ng mga nababad sa kanong kanluranin, silang mga nakatuntong sa paaralan. Inaakala lamang nilang nakauungos sila noon sapagkat priblihiyado nga ang panitikang Ingles. Gayon din nabansot si Villa. Hindi sapat ang pagtatago niya sa likod ng islogang "art for art's sake" upang hindi mailantad ang katotohanang naging tagapagtaguyod siya ng pamamayagpag 
ng kanong kanluranin. Noong binanggit niya ang kanyang posiyon sa The Best Filipino Short Stories of 1937, malinaw itong nagpakilala ng Villa na tumatalikod upang magamit ang panitikan bilang behikulo upang maunawaan ng mambabasa ang kanyang lipunan. Aniya:

A work of literature is not the more valid in that it records or contains a social upheaval-the validity of literature is independent upon no such purely circumstantial event, but upon the revolution of the internal personality of man...Literature lives because it is the portrayal of the eternal values, of the essences of things; it is the drama of the human soul and not the drama of the brokerage chart. $^{32}$

Habang itinatanggi ni Villa ang silbi ng panitikan sa kamulatan sa lipunan, siya at ang iba pang tagapagtaguyod ng awtonomiya ng sining ay nakulong din sa daigdig na hindi totoo sa kanilang buhay. Mag-aambag ito sa pagkilala sa mga akdang ituturing na hindi bababa sa toreng garing. Dagdag pa ni Jose Duke Bagulaya, iyon ang tanda ng superyoridad ng alagad ng sining. Ang artista at ang kanyang akda ay lampas sa limitasyon ng panahon at espasyo. ${ }^{33}$ Magiging pangunahing pamantayan ito ni Villa sa pagbuo ng sarili niyang kanon. Magdaragdag ito sa direksyong tinungo ng pagbuo ng kanong kanluranin. Dadalhin hanggang sa unang bahagi ng dekada sisenta ang maniobrang ito ng mga Amerikano. Mahihinuha kung gayon na dito nag-uugat ang paratang na "disyertong" kondisyon ng panitikang Pilipino sapagkat kay tagal nang panahon mula pa noong ikalawang dekada ay hindi ito malampasan nang ganap ng panitikang Pilipino.

\section{Ang mga Hugpungan: "Bagong Dugo" at Ang Quezonian at ang Antolohiyang Mga Agos sa Disyerto}

Nasuysoy kung gayon ni Efren Abueg, ang itinuturo ng kanyang mga kasama na siyang nagpanukala ng paggamit sa imahen ng "disyerto", ang kasaysayan ng pagkatuyot o pagkatigang ng panitikang Tagalog lalo na ng maikling kuwentong Tagalog. Aanihin nila ang bunga ng kamalayan ng kanong kanluranin at pagkagumon sa komersyalismo-ang pagsasantabi sa mga kuwentista at kuwentong Tagalog. Kasama ang mga kaibigang nakatagpo sa Liwayway at sa Manuel L. Quezon University, itong hamon ng pagkatuyot ang hinarap ng mga kabataang manunulat na bumuo ng antolohiyang Mga Agos sa Disyerto. Ang nabalahong pag-usad ng panitikang Tagalog (at maikling kuwentong Tagalog) na binuksan na ng henerasyon ng mga manunulat na Abadilla, del Mundo, Agoncillo, at iba pa ay binuhay at ipinagpatuloy na muli ng mga kabataang manunulat na isinilang sa mga namamayaning kondisyon ng dekada sisenta patungo sa dekada sitenta. Ngunit naiiba ito sa naging proyekto nina Abadilla, del Mundo at Agoncillo na bumuo ng antolohiyang sila ang tumayong kritiko at lumikha ng kani-kanilang 
pamantayan. Katulad lamang ng naunang naggiit ng pagbabago sa kalakaran, sina Rogelio Sikat, Edgardo M. Reyes, Efren Abueg, Eduardo B. Reyes, Rogelio Ordonez at Dominador Mirasol ay nakauunawa na malaking hakbang ang kailangan nilang gawin. Ngunit kung sisipatin, higit itong nagiging mabigat sapagkat binalikat nilang magkakaibigan ang antolohiya, kasama rito ang pagtatakda ng kanilang pamantayan sa sining. Ani Sikat:

Ang manunulat sa Tagalog ay kailangan pang patangay sa agos-at pagkaraa'y kailangan pa niyang sumubang pabalik sa halos walang agos niyang panitikan upang iyon naman ang pakatangkaing paagusin.

Upang mapakinis ang kanyang sining ay kailangan niyang huwag na mangalakal; ang kabataan ng panitikan ay kailangang bawiin niya sa pag-ukol ng kanyang buong panahon sa makasining na pagsusulat.

Kailangan niyang magwasak at bumuo. Kailangan niyang wasakin ang paniniwala, maging ng mga sumusulat na rin, na ang panitikan ay mga akdang inilalathala ng mga pang-aliw na magasin; kailangang wasakin niya ang maling pamantayan sa panitikan at kailangang itindig niya-at ipaalamang tamang pamantayan. ${ }^{34}$

Mula sa pahayag ni Sikat, malinaw na sa kanilang panahon ay umiiral ang pagagos ng panitikang komersyalisado, hindi pa rin makaalpas sa noon ay binanggit ni Agoncillo na pangangalakal sa paglikha. Ang espasyo ng seryosong paglikha ay lubhang maliit lamang. Kung kaya mula rito, sinabi niyang pangunahing dapat na isakatuparan ng matinong paglikha ay pagwasak sa lahat ng maling kalakaran at pamantayan. Subalit, pagkaraan naman nito ay sumunod naman ang pagkakaroon ng kapasidad sa pagbuo. Lubhang makitid ang pagkakataon upang madaling maisagawa ito ng grupo. Sa panahong iyon, hindi iilang beses silang tinanggihan hangga't hindi sila nagiging bihasa sa pormulang hinihingi ng magasing popular lalo na ng Liwayway na siyang may pinakamalawak na sirkulasyon noon. Upang maging "Bagong Dugo", ang mga kabataang magmamana ng trono ng matatandang manunulat ay hinahasa noon upang makatupad sa luma nang pormula sa pagsulat. Mahihiwatigan ito sa pahayag ni Agustin Fabian na, "Maghanda tayo ng mga manunulat na puwedeng sumunod sa atin." ${ }^{35}$ Hindi nila madaling mapapasok ang teritoryo ng matatandang manunulat na gaya nina Nemesio Caravana at Antonio Karasig na ang mga akda ay laging hinahanap ng mga mambabasa lalo na kung tahasan nilang sasalungatin ito. Ito ang sinasabi ni Sikat na "pagpapatangay" muna sa agos. Ngunit ito rin ang naging "break" upang kilalanin sila ng mga matandang manunulat na noong una ay siyang nagmomonopolyo sa paglalathala ng mga kuwento sa Liwayway. Ayon kay Edgardo M. Reyes, dumating sa punto na pagkaraang manalo siya bilang ang kauna-unahang Bagong Dugo na nagtamo ng gantimpala sa Palanca, nakapareha niya sa pagnonobela si Agustin Fabian. Binigyan 
din siya nito ng kapangyarihan na punahin kahit pa ang nobela ng matandang nobelistang si Amado V. Hernandez at ang kanyang Mga Ibong Mandaragit. ${ }^{36}$

Hindi naman natapos bago ang pagpasok ng dekadang iyon ang suliranin sa kabuhayan. Kung sisipatin malaki ang ginampanang papel ng ekonomiya sa pagdedetermina sa uri ng nailalathalang akda noon sa mga nagsusulat sa Pilipino at dahil kabilang sa gayong kaayusan ang mga manunulat-Agos, hindi rin sila makaliligtas dito. Ang unang bahagi ng kanilang karera sa pagsusulat ay pagsang-ayon sa kalakaran. Kailangan nilang kumita sapagkat lahat sila ay nagmula lamang sa mahirap na pamilya at ang kanilang pakikipagsapalaran sa lungsod ay pagkatagpo ng hindi madaling pamumuhay dito. Sa kalagayan halimbawa ni Edgardo M. Reyes, hindi niya noon maipagpapalit ang halagang ibinayad sa kanya sa pagsusulat sa kanyang kinikita sa pagiging piyon at pag-uupo niya ng kubeta sa mga konstruksiyon. Lubhang gipit ang buhay sa dekadang iyon.

Tinatayang umabot sa 7.5 porsiyento ng kabuuang populasyon ang bilang ng mga mamamayang walang trabaho. Hindi pa kasama rito ang libu-libong mamamayan na itinuturing na under employed. Noong 1968, tinatayang humigit-kumulang sa 1,100,ooo katao ang dami ng iskuwater; ang bilang na ito ay bumubuo sa 30 porsiyento ng populasyon ng kamaynilaan. ${ }^{37}$

Nang binuksan ng Liwayway ang pitak pang-estudyante na pormal na naipakilala bilang pitak ng "Bagong Dugo" nakapasok sa daigdig ng magasing popular ang maraming kabataang manunulat, kabilang na rito ang grupong bubuo ng Agos. Ito ang matutukoy na pasimula ng kanila munang "pagpapatangay" na sinasabi ni Sikat bilang noo'y mga indibidwal pang manunulat sa pagsulat ng mga kuwentong aprobado sa panlasa ng tagatangkilik ng naturang magasin-paksang magaan lamang, karaniwa'y pag-ibig, gayon din na de-kahong estilo ang banghay. Ito ang mga sangkap na hinahanap ng patnugutan ng Liwayway upang mapagdesisyunan kung ilalathala o hindi ang akda. Ilan sa mga nalathalang sinulat ng manunulatAgos na sumusunod sa pamantayang iyon ay ang mga kuwentong "Unang Patak ng Luha" ni Edgardo Reyes, "Dinurog ang Pamahiin" at "Kandila" ni Efren Abueg, "Sa Pagkahutok ng Puso" at "May Puwang ang Landas ng Puso" ni Rogelio Ordonez. Ngunit sa gitna ng mapanggipit na kalakarang ito, iginiit nila ang pagsulat ng mga kuwentong lumilihis sa pamantayan ng mga magasing popular, palibhasa'y mga nagsisipag-aral din sa kolehiyo ang karamihan sa kanila noon. Subalit, gaya ng inaasahan, hindi ito mapapalimbag. Naging espasyo-alternatibo nila noon ang mga pahayagang pampaaralan upang maipalathala ang pangontra sa komersyalisadong panitikan sa dekadang iyon. Subalit hindi rin lahat ng ito ay umayon sa kanilang iginigiit noong hindi kinakalakal na panitikan. Sa kalagayan ni Rogelio Sikat, bagaman mayroong The Varsitarian na maaring maglimbag ng kanyang "Tata Selo" sapagkat pahayagan ito ng UST kung saan siya nag-aaral, ay hindi pa rin doon unang matutunghayan ang akda niyang ito. May tatlong dahilan: una, lubhang 
konserbatibo ang pamantayan ng pahayagang pangkolehiyong iyon; pangalawa, mahihinuhang nakulapulan ang oryentasyon ng naturang pahayagan sa imaheng naitatak sa manunulat at panitikang Tagalog na mababang uri (nakaimpluwensiya rito ang "lugar" na inookupa nila sa lingguhang magasin na lubhang malawak ang distribusyon); at pangatlo, tinatangkilik ng UST ang dominasyon ng mga manunulat sa Ingles. ${ }^{38}$ Sa mga panahong iyon, sila-silang magkakaibigan ang tatangkilik sa uri ng panitikang inihahanda na nilang pangontra sa komersyalismo at sa mababang pagtingin sa panitikang Pilipino. Sa The Quezonian, ang editor sa seksyong Pilipino na si Edgardo M. Reyes ang maglalathala ng "Tata Selo" ni Sikat. Kung sisipatin, laganap na sa dekadang ito ang mga manipestasyon ng pagkakahati-hati--sa uri/kabuhayan (burges at masa), wika (Ingles at Filipino), kamalayan (akademya at popular) at maging sa mga unibersidad (UST, UP at MLQU). Matutunton din kung gayon na ang tumitingkad na kamalayan sa pagkakahati-hating ito ang magdadala sa pagbuwag sa gahum na itinutulak ng mga Amerikano. Nakita na ito halimbawa ng mismong MLQU sa malinaw nitong posisyong bilingwal sa wika. ${ }^{39}$ Liberal at progresibo rin ang may-aring dating Senador Lorenzo Tanada na siyang namamahala sa unibersidad. Gayon din na sa unibersidad na ito naganap ang unang malakihang pagbubuklod ng mga estudyanteng manunulat mula sa iba't ibang samahang pangwika at pampanitikan noong $1950 .{ }^{40}$ Kung kaya ang mismong The Quezonian ang tumatangkilik sa patas na espasyo para sa Pilipino at Ingles na mga manunulat ng pahayagang pampaaralang ito. Samantala, nasa kabilang panig ang UP bilang eskuwelahang itinayo at kinakalinga ng mga Amerikano, tutuparin nito ang pagpapalawak ng espasyo (halimbawa sa panitikan) para sa kapakanan ng kolonyal na edukasyong itinataguyod nito. Kung gayon, sa patakarang iyon ng MLQU, nakita ito bilang eskuwelahang tagatangkilik ng mga marhinalisado-ng uri ng panitikang di-tanggap ng pamantayang namamahay sa UP (at kahanay na paaralan gaya ng UST) at maging ng wikang walang puwang noon sa nasabing paaralan. Kung susuriin ang pahayag ni Ave Perez Jacob na proletarian university ang turing niya sa Manuel L. Quezon University (tingnan ang larawan 1 at 2), tinatanaw na niya itong pumosisyon kontra gahum. Ang The Quezonian ang magiging tahanan ng kanilang mga akdang itinuring na makasining, ang magtataguyod ng panitikang hindi pangkomersiyo lamang na nakasulat sa Pilipino.

Samantalang ganito ang pakikipaglaban ng grupong Agos sa maikling kuwento noon, nagsisimula na rin noon sa pakikipaggitgitan ang hanay ng mga kabataang makata. Naunang magpatalas sa makabagong pagtula sina Lamberto Antonio, Rio Alma at Rogelio Mangahas na namahay sa Dawn ng University of the East. Malinaw sa pagiging modernista ng mga makatang ito na tinaguriang "tungkongkalan" ng UE ang "paglampas" sa husay sa mga limbag sa magasing komersyal. Sa bakuran naman ng Ateneo de Manila University ay isinilang ang panulaang "Bagay" na unang ipinakilala ng mga makata (binubuo ng mga estudyante, guro at paring Heswita) na sina Jose Lacaba, Edgar Alegre, Rolando Tinio, Bienvenido Lumbera, Edmundo Martinez, at Antonio Samson. ${ }^{41}$ 
Kung susuriin, umangkop din sa mismong ipinaglalaban ng grupong Agos ang institusyong kakalinga sa kanilang adhikain_ang Manuel L. Quezon, unibersidad na ipinangalan sa pangulong kinilala bilang tagapagtaguyod ng wikang pambansa. Ito ang unibersidad na tumatangkilik sa Pilipino at kinilala bilang eskwelahan ng mahirap. Sa panahong iyon, sa MLQU mamahay ang mga rebeldeng katulad nila sapagkat walang pagtangkilik silang maasahan sa iba pang unibersidad na nagdeklara na ng pagtangkilik sa kolonyal na edukasyon at samakatwid ay tumanggap sa dominasyon ng kolonisador sa wika at panitikan. Inangkin na rin ng MLQU ang dangal bilang espasyong nagpasibol sa marami nang mahuhusay na manunulat bago pa man ang mga manunulat-Agos. Sa isang bahagi ng pahayagang The Quezonian, ganito ang pahayag ng isang artikulo:

Sa kasalukuyan ay masasabing ang panitikang Tagalog sa ating pamantasan ay nasa kanyang kasibulan at kaningningan. Hinihingi ng pagkakataon at makatarungan naman kahit sa ilang saglit minsan sa isang taon na lingunin ang nakaraan. Ito lamang ang tanging paraan upang kahit papaano ay maaaninag natin ang nakaraan, makilala, dagdagan ang kaalaman kahit sa panulat ang mga nauna sa atin, mga mag-aaral na ang angking kaisipan at panulat ay nagkatulung-tulong upang ang ating pamantasan ay makilala sa Panitikang Pilipino.

Hindi na nararapat pagtalunan pa ang paniniwalang ang Panahong gintung-ginto ang mga dahon ng Quezonian ay ang kapanahunan nina Ponciano Peralta Pineda, Gonzalo Flores, Bienvenido Hernandez, Manuel Ocampo, Fernando Samonte, Buenaventura Medina at Bienvenido Mata at marami pang iba. ${ }^{42}$

Habang may malinaw na proyekto para sa Ingles ang mga Amerikano sa tukoy nitong mga unibersidad, naging tahanan ang Manuel L. Quezon University para sa mga manunulat sa Tagalog.

Ani Bagulaya:

In relation to the literary field, the US educational system produced an Englishliterate public from which readers and writers emerged. The educational institutions then were central to the production of producers and readers who were crucial in the formation of a literary field. Among the colonial schools, the founding of the University of the Philippines (UP) in 1908 was decisive. ${ }^{43}$

Sa pamamahay nila sa tinaguriang proletarian university ni Jacob, nabanggit niya sa interbyu na nasa artikulong "Mga Agos sa Disyerto: the Agony and the Ecstasy of Writers in Pilipino," noong 1989 na isinulat ni Melanie Manlogon, na habang humuhubog ng ganoong produkto ang mga elite na unibersidad na tulad ng UP, 
pinanindigan ng grupo ang paggamit sa wikang Pilipino sa mga kuwentong kanilang isinulat. Habang kinakailangan nilang sumulat sa mga magasing pangkomersyal upang kumita at makilala, sinimulan na nilang magkakaibigan ang pagsulat ng mga kuwentong humaharap na sa namamayaning kondisyon o kalagayan ng bayan. Isisilang ang kanilang mga kuwentong nakatanaw nang papaloob at nag-uusisa sa kalagayan ng bansa at kasabay nito ay ang pagsusulong ng panibagong pamantayang naging pasimula

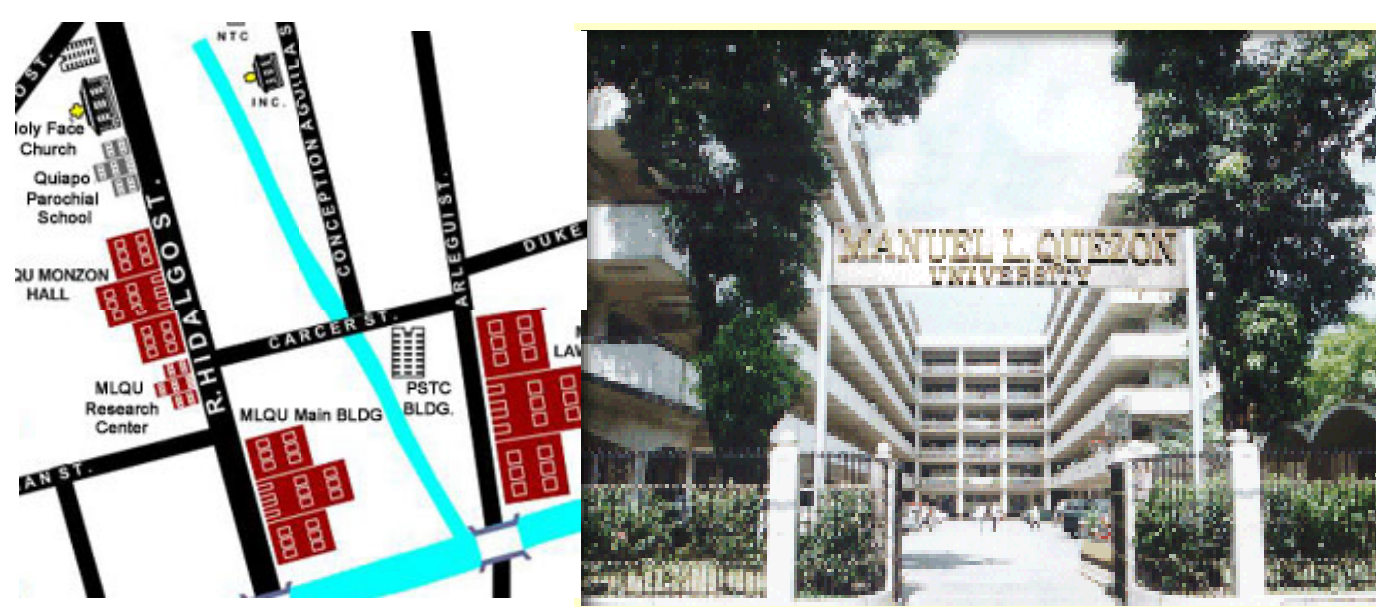

Larawan 1: Ang MLQU at ang lokasyon nito

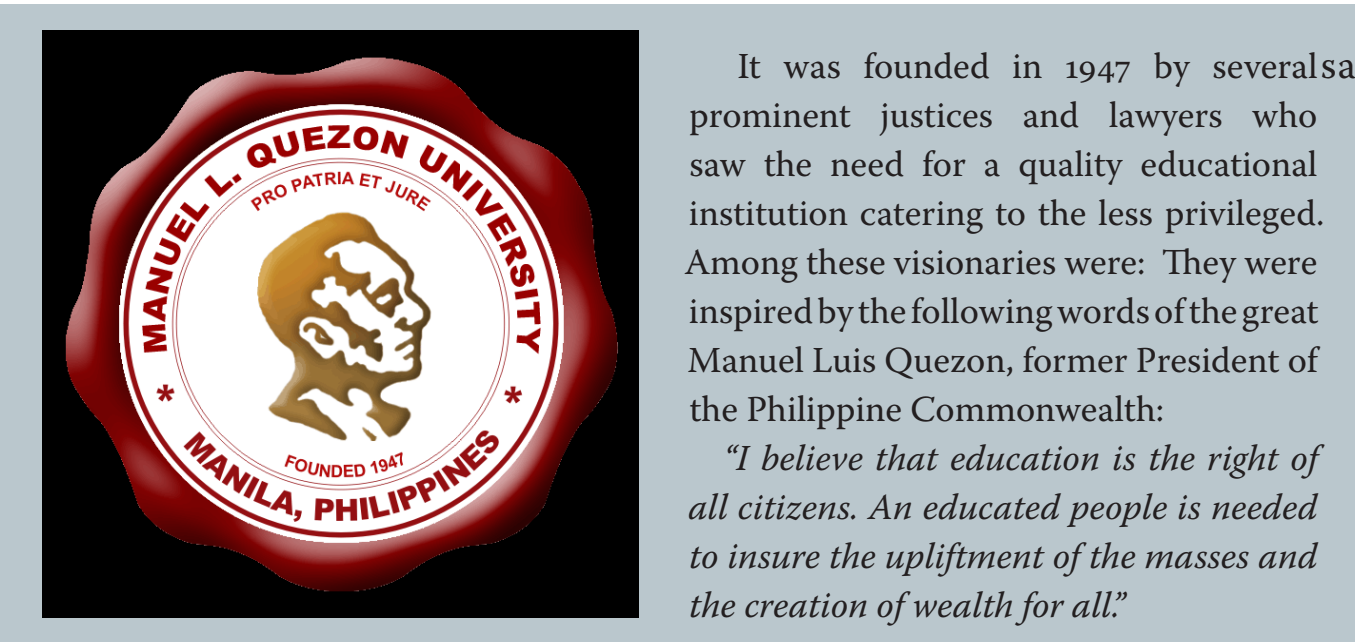

Larawan 2: Logo ng MLQU at Bahaging pahayag ng Kasaysayan ng MLQU

pagbabago ng panlasa ng mga mambabasa. ${ }^{44}$ Sa isang banda ito ang ginamit nila 
sa paglihis sa namamayaning ideolohiya noon. Sa ganitong pagkilos hindi na maitatangging umiiral ang grupong Agos sa isang panahon kung saan laganap na ang mga progresibong pagkilos.

Hindi nagtagal sa mga pahina ng Liwayway ang ilang kabilang sa "Bagong Dugo" na siyang bubuo ng Agos. Ipinakita nila ang kanilang sariling paninindigan at pananaw sa panitikan. Ito ang naghudyat ng hindi pagkakaunawaan sa panitikan ng grupo at ni Liwayway Arceo na ginawang tagapamahala ni A.C. Fabian sa mga "Bagong Dugo"45 Matapang at himig rebelde ang pahayag na ipinarating ng grupo, anila:

...ang paghiwalay na ito ay tulak ng paghahanap nila ng istilong pagpapahayagan nila ng damdamin at kaisipan ng kanilang sining na iba sa pamamaraan at pagpapahayag ng idea ng nagtuturo sa kanila... ${ }^{46}$

Maging si Rogelio Sikat ay may indibidwal na pagtingin sa kanyang pasya ng pagtiwalag sa Liwayway. Para kay Sikat, hindi ang magasing iyon ang magbibigay laya sa kanya bilang manunulat. Isa itong instrumentong tumitigpas sa sining ng manunulat sa Pilipino. Ang pananatili rito ay pagpapakulong at pagsunod sa adhikain nitong magbigay lamang ng ikinababa ng mga manunulat at mambabasang Pilipino. Ani Sikat:

Biglang-bigla, naisip ko ang Liwayway. Bakit nilalayuan ito ng mga manunulat? Bakit nagbitiw ako rito noong 1961? Nailing ako nang maisip kong kaya ako umalis doon ay dahil hindi ako makahinga roon; pinipigil doon ang laya ng guni-guni, iniinis at waring sinasakal. ${ }^{47}$

Hindi mga "karaniwang" kuwentong limbag sa magasing komersyal ang ipapagitna ng ipinalimbag nilang koleksyon ng kanilang mga kuwento kundi mga premyado-sinuri at kinilala ng mga hurado/kritiko ng mga patimpalak na kanilang nilahukan. Sa Carlos Palanca Memorial Awards for Literature, nanalo ang "Mga Aso sa Lagarian”, Unang Gantimpala, "Impeng Negro" at "Tata Selo", kapwa Pangalawang Gantimpala, "Mapanglaw ang Mukha ng Buwan”, “Di-Maabot ng Kawalang-Malay", "Mabangis na Lunsod", "Sa Bagong Paraiso" at "Dugo sa Ulo ni Corbo", lahat ay pawang nagwagi ng Pangatlong Gantimpala sa iba't ibang taon ng patimpalak. Ginawaran din ng KADIPAN ng unang gantimpala ang "Dugo ni Juan Lazaro". Itong mga premyadong akdang ito ang pangunahing tanda ng kanilang pagtanggi sa imaheng ikinakabit sa panitikang Pilipino at sa pamantayang kailangang tupdin upang sila ay "mapabilang".

Naging pribilihiyadong panitikan ang pagsulat sa Ingles sa ilalim ng Amerikanong sistema ng edukasyon, at sa panahong nabuo na ang UP Writer's 
Club noong 1927, iniangat nito sa pinakamatayog na luklukan ang wikang Ingles na may islogang "Art shall not be a means to an end but an end in itself..

Gamit ang Ingles bilang wikang panturo, ang pag-aaral pampanitikan ay nakabuo ng kanong pampanitikan na patuloy na itinuturo. Hanggang ngayon, ang pag-aaral ng kanong pampanitikan sa akademya ay nanatiling kanluranin, may pagkiling sa mga limbag na akdang itinuturing na "genres of imaginative writing" (maikling kuwento, tula at dula), at sinuri sa pamamagitan ng pamantayang pormalista. (akin ang salin) ${ }^{48}$

(Writing in English under the American school system thus became a privileged literature, and, by 1927, the writers on campus had formed the UP Writer's Club to "elevate to the highest possible perfection the English language," with the shibboleth, "Art shall not be a means to an end but an end in itself...

With English as the medium of instruction, literary studies acquired and developed a literary canon that continues to be taught. Even today, the literary canon in the academe remains heavily Western, with the bias for printed works only in the genres of imaginative writing (e.g. fiction, poetry, and drama), and critically selected through formalist criteria or standards.)

Hindi ang alinmang institusyon o mga praktis ang kanilang sasandigan upang umokupa ng posisyon o lugar para sa manunulat at maikling kuwentong Tagalog. Kailangan nilang lumikha ng karunungang magtataguyod ng kanilang pakikipagtunggali kontra sa marhinalisadong kalagayang ito. Produkto ng dominasyon ng Ingles ang nagharing pananaw sa panitikang tumalikod sa realidad ng buhay. Ito naman ang magiging puhunan ng mga manunulat-Agos upang lumikha ng kasaysayan ng pagbabago sa panitikan na siya mismong marhinalisado. Sa pamamagitan ng nilikha nilang mga akda, humubog sila ng bagong pamantayang tiwalag sa itinatakda ng naghaharing pamantayan. Sa ganoong direksyon dinala ng Mga Agos sa Disyerto ang maikling kuwentong Tagalog (Pilipino) sa mga huling bahagi ng dekada singkuwenta at sisenta. Pinili nilang iharap sa mambabasang Pilipino ang realismong panlipunan. Ito ang eksaktong kabaligtaran ng lahat ng itinatakdang ipinapasulat sa kanila ng mga magasing popular na mga de-kahong kuwento, pantasya at romansa. Ito ang panagot nila sa maniobra ng aliw, pantasya at romantisismo na lumikha ng mababang pagtingin sa manunulat sa Pilipino at nagpalimot sa mga dapat harapin ng mambabasang Pilipino. Ito ang magdedeklara ng panibagong pagrerebelde sa maikling kuwentong Tagalog (P/Filipino) upang makapasok ang "bago" na kaagapay at tumutugon sa panahon. Kung sisipatin, sa paglabas ng Mga Agos sa Disyerto naipakilala nito ang rebeldeng-panindigang moderno sa pagtalikod sa lahat ng kalakaran/sistemang itinakda ng namamayaning mga praktis (komersyalismo ang isa rito) na pinakinabangan ng mga manunulat sa Ingles at ng mga Amerikano. 
The more significant manifestation of modernism, to us, is an attitude of mind-an outlook, an orientation, a perspective, a world vision-which has for its object both personal and social/national development. Consequently, the ever critical eye directed on the status quo, on the traditional ways, is with the intention of improving still the quality of life... [akin ang pagdidiin $]^{49}$

Naghudyat ng pag-agos muli ng buhay at ng iba nang direksyon para sa maikling kuwentong Tagalog (P/Filipino) ang piraso ng kasaysayan at makabuluhang pagkilos na ginawa ng antolohiya laban sa panahon at kalakarang kanilang kinapapalooban. Ito naman ang magiging puhunan ng mga manunulat na isisilang ng "mainit" na dekada sitenta.

\section{Ang Pamantayan ng Mga Agos sa Disyerto-Panimulang Pagpapaagos}

Matutukoy na may tatlong puwersa na kinailangang malupig ng sinumang manunulat sa panahong kinapapapalooban ng grupong Agos. Pawang magkakaugnay ang pagkauso ng komersyalismo na naging bitag upang isuko ng mga manunulat sa wikang Pilipino noon ang kanilang sining na humaharap sa realidad, ang pagpapalaganap ni Villa at ng kanyang mga kapanalig ng pamantayang unibersal sa sining at ang pagpapaubaya ng mga Pilipino sa pangingibabaw ng sistema ng edukasyong maka-Amerikano na tumangkilik sa kanong Ingles. Ang lahat ng ito ay maniobra upang mapanatili ang status quo-segunda klase lamang ang panitikang Pilipino sa tabi ng produksyon ng mga manunulat sa Ingles subalit higit pa roon, segunda klase lamang ang lahing Pilipino. Mababago lamang ang kalagayan ng mga manunulat sa Pilipino kung gagagarin nila ang modelong hango sa Amerika, magsa-anyong/mag-isip Amerikano upang "tangkilikin" din ng estado. Magkakaroon lamang sila (at ang mga Pilipino) ng halaga kung kalilimutan ang pamantayan ng pagkaunawa sa ubod/sentrong loob ng bayan. ${ }^{50}$ Sa mga salita ni Sikat_-"nakatanaw sa labas ng bansa, sa Amerika."51 Ganito rin katapang si Rogelio Ordonez sa kritika niya sa masagwang ibinunga ng pagka-Amerikano ng mga manunulat at kritikong Pilipino. Aniya:

'Yung kondisyon nila roon hindi naman puwedeng ilapat sa kondisyon natin sa Pilipinas. Kagaya ng edukasyon, our education was copied piece by piece from American education whereas our economy doesn't match American industrialization. Tapos heto tayo ngayon para tayong copycats...literary theories natin tingnan natin sa ating kultura, iyong ating way of life as Filipinos...Huwag nating gawing basehan ang western literary canon. ${ }^{52}$ 
Makikitang ginabayan ng namamalas at dinaranas na kalagayan ang naging pagsusuri at pagtataya ng mga manunulat-Agos sa pagbuo ng magiging isa sa mga pang-iskrin nilang magkakaibigan sa mga kuwentong isinulat nilang may kabuluhan at nakauugnay sa loob ng bayan. Ito ang kritikal nilang sipat sa status quo na ayon kay Melendrez-Cruz ay pinanahihintulutan dahil umano naglalayong mapaayos pa ang buhay. Hindi sila madaling mapararatangang ignorante sapagkat gagamitin nilang lisensya ang edukasyong ${ }^{53}$ parehong ginagamit na sangkalan ng mga manunulat sa Ingles. Kung ano ang ginawang marhinalisasyon ng mga manunulat sa Ingles sa mga manunulat sa Pilipino ay siya ring ginawa ng mga manunulat-Agos. Subalit, hindi lamang ang disipulo ng pamantayang Amerikano ang hahamunin ng pamantayang Agos kundi maging ang mga manunulat na tinawag ni Ave Perez Jacob na nagpoprodyus ng tradisyonal na panitikan. Walang nakasulat na pamantayan (gaya ng written treatise) patungkol sa kanilang nilalabanan noon ang grupong Agos di tulad ng PAKSA. Sa katotohanan, ayon sa panayam kay Edgardo M. Reyes at Rogelio Ordonez, nagsimula lamang sila sa ideya ng pagbibigay ng kuwentong sa kanilang tingin ay ang tatlo o limang pinakamahusay na nilang nagawa. Ani Reyes, "Nung panahon na iyon, the best na iyon." ${ }^{4}$ Ayon naman kay Ordonez, "... kanya-kanyang pili at bigay kay Efren..." ${ }^{55}$ Subalit, mahihiwatigang may konteksto itong "pinakamahusay na nagawang kuwento" na isinama ng bawat manunulat sa binuo nilang antolohiya. Nasa panahon sila ng namamalasak na mga komersyal na akda na makikita sa mga komersyal na magasin. Samakatwid nauunawaan nilang ang mga "pinakamahusay" at "pili" na isasama nila sa antolohiya ay ang eksaktong kabaligtaran na hindi nangyayari sa mga naglipanang komersyal na akda. Malaki ang naging implikasyon nito sa sitwasyon noon ng panitikang Tagalog. Binubuwag nito ang matagal nang umiiral na paniniwala sa kawalang-kapasidad o kakayahan ng panitikang nakasulat sa Tagalog. Pinupuna nila ang paglulunoy sa romansa ng mga komersyal na akda. Pinupuna rin nila ang maling pagkilala sa matayog na kalagayan ng panitikang nakasulat sa Ingles. Nauna na itong pinuna ni Rogelio Sikat. Aniya, habang nakapaglalakbay sa pandaigdigang panitikan ang mga nagsusulat sa Ingles dahil sa paggamit sa Ingles, sila naman sa paggamit ng Pilipino ay ang pangkat na tumitingin namang papaloob. ${ }^{56}$ Gayon may oportunidad man na bukas sa mga nagsusulat sa Ingles, hindi naman nito maangkin ang espasyo ng mga nagsusulat sa Pilipino na laging may kapasidad na tumingin nang papaloob o sa sarili nito. Mula sa konteksto at direksyong tinahak ng Mga Agos sa Disyerto, mahuhugot din ang mga pamantayang gabay sa kanilang mismong pag-aantolohiya: una, mga kuwentong tumitinging papaloob; pangalawa, hindi hinubog ng mga tradisyonal na pamantayan ng mga kuwentong aliw at pantasya lamang sa halip ay naglalantad ng tunay na mukha ng realidad at lipunang Pilipino at pangatlo, maitatawid walang iba kundi ng wikang Pilipino. Bago pa man maging laganap ang konsepto ng major, minor at minority ${ }^{57}$ sa panitikan nang dekada nobenta, makikita na ang paggigiit ng mga kuwentong-Agos ay paggigiit din ng pamantayang magpapakilala sa kanila bilang nasa laylayang humahamon sa sentro. Mahahayag ang pagpapahalaga ng 
mga manunulat-Agos sa tatlong nabanggit na nagbibigkis-sa-kanilang-pamantayan. Sa paliwanag nga ni Ordonez, ukol sa pamantayan ng magandang kuwento noon, aniya:

Form at content dapat complimentary iyan... Isang babae 'ka ko, genius, galing, walking encyclopedia, et cetera, eh, duling? 'Ka ko nababawasan din ang ganda niya. Basta 'ka ko, form and content complimentary dapat...Tapos pangatlo, language. Ang galing ng form mo, ang galing ng content mo, eh ang ginagamit niyo 'yung wika na padaskol-daskol. Pilay. Hindi ba 'ka ko nababawasan 'yung ganda?... Then relevance. Okay, hetong kuwento mo, ang ganda! Ang ganda ng estilo mo, porma mo, 'ka ko naman ang topic mo ay drakula at aswang, o kabayong lumilipad... ${ }^{58}$

May ganito ring paraan ng pag-uuri si Edgardo M. Reyes sa mga kuwentong maituturing na may halaga o wika nga niya ay "literary". Magaganap ito pagkaraang mapagod siya sa pagsulat ng mga kuwentong hindi masilipan ng technical error subalit anya ay pawang kuwento ng kabugukan lamang. Mga kuwentong aniya ay "walang kuwenta 'yung istorya, pero magkakapera ako." ${ }^{59}$ Paraan ang pagsulat niya noon upang makalampas sa hirap ng buhay niya noon. Subalit ganito man kilala niya ang kanyang sarili, dagdag pa niya, "Alam ko kung kailan ako magsusulat ng panghanap-buhay at kung kailan ako magsusulat ng kuwento." ${ }^{\prime 60}$ Nang matutong "bumasa" si Edgardo Reyes ng Hemingway, kasama ang mga ka-Bagong-Dugo, ang pinagsimulan ng marami sa manunulat-Agos, iniangat nila ang pamantayan ng itinuring nilang "literary" para sa kanila. Iniwasan ang mga gasgas na paksa, maging ang mga gasgas na paraan ng pagpapahayag. Ang mga iyon ang alam noon ni Reyes at dati niyang puhunan upang kagiliwan siya ni A.C. Fabian.

Nagbabasahan kami. 'Pag bumanggit ka ng katagang "puso", ililibing ka nang buhay. Wala sa amin iyong nalulungkot, itong nasa bintana, "huminga ng malalim, tumanaw sa malayo, bumuntonghininga”. 'Yung, halimbawa'y iniwan ka ng asawa mo’y para kang pinagtakluban ng "langit at lupa”. Itatakwil ka ng grupo 'pag gumamit ka ng salitang 'yan. ${ }^{61}$

Sa gayong direksyon, sa karanasan ni Reyes, lalong naging malinaw ang pagsulat na pampanitikan (literary) paminsan-minsan ay tinatawag niyang "pampalanca". Ang isa sa mga kuwentong nasa Mga Agos sa Disyerto, ang "Di-Maabot ng KawalangMalay" ang umani ng batikos kay A.C. Fabian na nagsabing "A long, long short story about nothing," ${ }^{2}$ ang humamon sa komersyalismo at nag-angat ng luklukan mula sa pagiging komersyal na manunulat ni Reyes at sa pagiging "mababa" ng maikling kuwento sa Pilipino. Nang pauyam na itinanong ni Reyes kay A.C. Fabian kung ano ang dapat nilang sulatin, "iyong dapat isulat" kaysa sa "magugustuhan ng mga mambabasa,"63 idineklara na ni Reyes ang pagkaunawa at pagtangkilik sa 
pampanitikang akda kaysa komersyalisadong likha. Nanalo ang kuwentong iyon sa Carlos Palanca Memorial Awards for Literature.

Maraming kinailangang basagin ang Mga Agos sa Disyerto. Una na rito ay ang pamantayan ng mga palimbagang komersyal gaya ng Tagumpay, Aliwan, Bulaklak at ang pinakamalakas na Liwayway na hindi pumapayag na hindi mapagsilbihan kung ano ang "gusto" ng mga mambabasang Pilipino. Nang pinagdamutan sila ng mga ito, naging mabuti pa rin ang tadhana sa mga kabataang manunulat na gaya nila ng panahong iyon. Kahit papaano naging espasyo nila ang mga pahayagang pangkolehiyo sa isang pahinang seksyong Pilipino bagaman isa lamang ang tunay na naging "hasaan" nila sa pagpapakinis ng kanilang pagsulat, ang The Quezonian (lubhang konserbatibo at teritoryo ng mga nagsusulat sa Ingles ang The Varsitarian ng UST na unibersidad ni Sikat). Ngunit hindi kaila sa magkakaibigan na hindi magiging malawak ang impluwensya nito at kung may nais silang mabago sa mismong kalakaran at pamantayan sa maikling kuwento sa Pilipino. Malawak na sirkulasyon ang kailangan nila. Ang distribusyon ng pahayagang pangkolehiyo ay ni wala pa sa sampung porsyento ng Liwayway. Sa journal ni Sikat na naisulat niya noong 1979, noong mga panahong iyon, aniya, ang sirkulasyon ng Liwayway ay 170,00o linggo-lingo. Isang antolohiya na naglalaman ng kanilang "hindi-nakailangang-bigkasing-pamantayan" at pawang premyado ang kanilang itinapat sa mga publikasyong komersyal upang wari ay pormal nang ideklara ang pagbabagong landas na dapat nang tunguhin ng maikling kuwentong Pilipino. Maliit na bilang ang 856 na kopya sa unang edisyon na limbag noong 1965. Maliit na populasyon ng mambabasang Pilipino kung sakali ang mababago ng antolohiya upang mailipat at makakawala sa, ayon nga kay Sikat, ay lumang tradisyon ng panitikan. Subalit, iyon ang kanilang idineklara, ayon nga sa kanilang panimula:

Ito ang ibig naming gawin. Ibig naming ipabasa sa bayan ang mga bagong akdang sa abot ng aming kaalaman at kasanayan ay tinipon namin at sa kabila ng mga sagabal sa pagpapalimbag ay naipagsumakit naming maiharap sa bayan. $^{64}$

Pagkaraang mapalimbag ang unang edisyon ng 1965, kikilalanin ng mga kritiko ang naisakatuparan ng antolohiya. Isinulat ni Pablo R. Glorioso ang "The Desert in Tagalog Literature" sa Saturday Mirror noong Marso 13, 1965, ang pagsusuri niya sa mga kuwentong sa wari niya ay isinulat ng "isang manunulat" lamang sa pagkakaugnay-ugnay ng mga ito sa estilo at nilalaman. Isinama naman sa Brown Heritage ni Antonio Manuud ang kritisismo ni Bienvenido Lumbera na "Rehabilitation and New Beginnings: Tagalog Literature Since the Second World War" na nagpahayag ng papuri niya sa grupong Agos. Napagtagumpayan ng grupong Agos ang paghulagpos sa mga itinakwil nilang pagsulat ng kuwentong iginigiit ng mga komersyalisadong magasin. Ani Lumbera: 
As a collection, Agos sa Disyerto is outstanding in many ways. But what is most impressive about the writing it contains is its avoidance of the usual flaws of Tagalog fiction-worn-out themes, idealization of materials, erratic use of point of view, meaning that is left unrealized for lack of particularity of detail. ${ }^{65}$

Sa mga kritikong-aral na gaya nina Glorioso at Lumbera na nagbigay ng panahon upang sipatin ang Mga Agos sa Disyerto, naipakilala na sa mambabasang Pilipino ang limang nagdeklarang hahawi sa "disyerto" na kalagayan ng maikling kuwentong Pilipino. Ayon kay Lumbera, naging interesado pagkaraan ang mga mag-aaral at guro ng panitikan sa antolohiya. ${ }^{66}$ Mahalaga ring banggitin na magpapasimula na ito ng unti-unting pagkilala sa mga manunulat sa Pilipino na mapapabilang sa kanon na ipababasa na sa mga mag-aaral na Pilipino. Isang magandang halimbawa rito ang pagbabagong kailangang gawin ni Asuncion David-Maramba, isa sa mga edukador na humubog ng kanon na binasa ng mga mag-aaral sa sekundarya at tersyarya at naglimbag ng anim na edisyon mula 1962 hanggang 1990 ng kanyang aklat na Philippine Contemporary Literature. Mula sa kanyang panimula para sa ikatlong edisyon ng 1970, mahihinuha na noon lamang niya isinama ang mga manunulat sa Pilipino sa kanyang aklat, na umuutang ng loob kay Bienvenido Lumbera sa pagtulong nito sa seksyong Pilipino. Sa seksyong ito, dalawang akda na matatagpuan sa Mga Agos sa Disyerto ang napabilang ang "Mapanglaw ang Mukha ng Buwan" ni Efren Abueg at ang "Impeng Negro" ni Rogelio Sikat. ${ }^{67}$ Patunay ito na kung pag-uusapan ang kung ano ang naging pagtanggap ng mga mambabasa sa antolohiyang Agos ay nasa tagumpay nitong mapasok ang kanong inilalaan lamang noon para sa mga manunulat sa Ingles. Marami na ring kilalang manunulat ang magbibigay ng papuri sa aklat sa ikalawang edisyon nito noong 1974. Magiging bahagi na ng ikalawang edisyong ito ang mga "sinasabi" nina Gervasio B. Santiago, patnugot ng Liwayway, Lucy De Guia, manunulat ng Philippines Herald, Jose Villa Panganiban, dating patnugot ng Surian ng Wikang Pambansa, Ponciano B. Peralta, direktor ng Surian ng Wikang Pambansa at Dr. Rufino Alejandro, dating Pinunong Pampangasiwaan ng Kagawaran ng Edukasyon. Ang mga ito ang nagsisilbing patunay sa lawrel ng grupong Agos, kasama ang katotohanang pangalawang edisyon na ito ng antolohiyang naghangad na mapatunayang tapos na ang panahon ng pagka-disyerto ng panitikang Tagalog. Lalo pang mapatitibayan ang positibong resepsyon (pagtanggap) ng mambabasang Pilipino sa kanilang antolohiya sa muling pagpapalimbag ng ikatlo nitong edisyon noong 1993. Ayon kay Rogelio Ordonez, ang maraming kopyang nalimbag mula unang edisyon na 856 sa palimbagang Pilipino hanggang sa paglipat nito sa National Bookstore bilang pabliser ng kanilang antolohiya ay patunay na marami ang nagbabasa ng kanilang antolohiya. ${ }^{68}$ 
Tunay na mula sa panahong marhinalisado ang mga manunulat sa Pilipino, naisakatuparan ng noo'y kabataang rebelde ang kanilang adhikaing may mabago kundi man ganap na mabago ang trato at pagkilala sa panitikang Pilipino. Subalit, matayog pa rito ang pangarap ni Rogelio Sikat. Nais niyang walang maiiwang anumang mababang paningin sa panitikang Pilipino lalo na at, dapat sa panahong ito ay nalampasan na ang mga akdang hindi humahamon sa paghahari ng Ingles. Sa journal ni Sikat, matalinghaga ang pahayag niya sa kahandaang yapusin at pangatawanan ng manunulat sa Pilipino at ng panitikang Pilipino ang kapangyarihan ng sentrong kikilalanin ng mambabasa. Ani Sikat:

Sa yugtong ito ng panitikan, ano kaya't bukas ay biglang mawala ang Ingles, kasama na ang mga akdang isinalin sa wikang ito? Ano ang matitira? Bukod sa kakaunting nobela't libro ng tula, mga manuskrito ng dula, matitira ang Liwayway, sa mga magasin; ang madalang nang lumabas na Sagisag; sa mga diyaryo, matitira ang mga kolum na "Abot-tanaw" ni Ligaya David Perez (Daily Express); "Busal at Butil" ni Rolando Ocampo Fadul (Bulletin Today); at "Sa Paligid-ligid" ni Dionisio S. Salazar (Times Journal). Matitira rin ang Balita at Pilipino Express; matitira ang mga komiks; si Rod Navarro sa radio; si Inday Badiday sa TV; Ang Dalagang Pinagtaksilan ng Panahon sa pelikula. ${ }^{69}$

Sa talahanayan 1 sa ibaba makikita ang lagom ng mga pangyayaring pinagdaanan ng maikling kuwentong Pilipino at ang pagbuo ng mga kalipunan o antolohiya bago ang pagkabuo ng Mga Agos sa Disyerto.

Talaan $1^{1}$

\begin{tabular}{l|l} 
PETSA & PANGYAYRI \\
\hline \multirow{1000}{*}{$\mathbf{1 9 1 0}$} & $\begin{array}{l}\text { Pamumutiktik ng mga instantanea sa prosa romantica na } \\
\text { nakaimpluwensiya sa direksyon ng dagli. }\end{array}$ \\
\hline & $\begin{array}{l}\text { Pinabangon ang antas ng maikling kuwento mula sa } \\
\text { impluwensiya ng kalakaran ng dagli sa pagbubukas ng } \\
\text { patimpalak-paniitik ng pahayagang Mithi. }\end{array}$
\end{tabular}

1 Mula sa journal ni Rogelio Sikat na may pangkalahatang pamagat na "Hindi Ngayon ang Panahon at iba pang Tala". Binigyan ng tiyak na pamagat ang journal entry na "Ang Kaunting Matitira". Walang petsa. 


\begin{tabular}{|c|c|}
\hline PETSA & PANGYAYARI \\
\hline 1920 & $\begin{array}{l}\text { Marami pa ring dagli ang pumaksa sa pag-ibig subalit } \\
\text { mayroon na ring lumandas sa tradisyon ng makabayang } \\
\text { panitikan ng propaganda at himagsikan. } \\
\text { Naitatag ang lingguhang Liwayway. }\end{array}$ \\
\hline 1927 & $\begin{array}{l}\text { Inilabas ni Clodualdo del Mundo ang Tao sa Parolang } \\
\text { Ginto } \\
\text { Inilabas naman ni Jose Garcia Villa ang kanyang "Honor } \\
\text { List" at "Horror List" para sa mga maikling kuwentong } \\
\text { isinulat sa Ingles ng mga manunulat na Pilipino. }\end{array}$ \\
\hline 1932 & $\begin{array}{l}\text { Inilabas ni Alejandro Abadilla ang Talaang Ginto at } \\
\text { ipinagpatuloy ang Kapisanang Kalipunan ng Kuwentista at } \\
\text { Ilaw at Panitik. }\end{array}$ \\
\hline 1937 & $\begin{array}{l}\text { Nag-ibayo ang hangaring iangat ang Panitikang Tagalog sa } \\
\text { pagkabuo ng Ilaw ng Bayan na pinasimulan ni B.L. Rosales. }\end{array}$ \\
\hline 1939 & $\begin{array}{l}\text { Lumabas ang koleksyon ng } 50 \text { Kuwentong Ginto ng } 50 \\
\text { Batikang Kuwentista ni Pedrito Reyes na ayon mismo } \\
\text { kay Reyes ay koleksyong hindi na dumaan sa panunuri ng } \\
\text { sinomang kritiko. }\end{array}$ \\
\hline 1940 & $\begin{array}{l}\text { Pagsusunog ng mga akdang hindi dapat ikinararangal } \\
\text { kapwa ng matatanda at kabataang manunulat sa } \\
\text { panawagan/impluwensiya ng noo'y lumalakas na grupo } \\
\text { ng mga kabataang manunulat na humihingi ng espasyo sa } \\
\text { lingguhang magasin. Naganap ito sa Liwasang Moriones sa } \\
\text { Tundo na pinangunahan ng mga taga-Panitikan. }\end{array}$ \\
\hline 1943 & $\begin{array}{l}\text { Inilabas ang } 25 \text { Pinakamahusay na Kathang Pilipino ng } \\
1943 \text { na umano'y dumaan sa masinsinang pagbasa ng } \\
\text { lupong tagasuri na may ginamit na panukat. Bunsod ito } \\
\text { ng panghikayat ng pamahalaang Hapon noong panahon ng } \\
\text { kanilang okupasyon/pananakop sa Pilipinas na tangkilikin } \\
\text { at itanghal ng mga Pilipino ang sariling kultura sa panitikan. }\end{array}$ \\
\hline
\end{tabular}




\begin{tabular}{|c|c|}
\hline PETSA & PANGYAYARI \\
\hline 1944 & $\begin{array}{l}\text { Pagdagsa ng mga magasing Saga-Saga, Pag-asa, Sinagtala, } \\
\text { Bulaklak na dagdag pa sa noo'y naghaharing Liwayway at } \\
\text { ng mga komersyal na akda. }\end{array}$ \\
\hline 1952 & $\begin{array}{l}\text { Naglabas ng sariling antolohiya si Genoveva Edroza Matute } \\
\text { na pinamagatang Ako’y Isang Tinig. }\end{array}$ \\
\hline 1954 & $\begin{array}{l}\text { Nalimbag ang Ang Maikling Kathang Tagalog na } \\
\text { pinamatnugutan nina A. Abadilla, F.B. Sebastian at A.D.G. } \\
\text { Mariano. Kabilang sa antolohiya ang mga akdang naunang } \\
\text { pinarangalan ng Taliba, Talaang Bughaw, Liwayway at } \\
\text { Palanca. }\end{array}$ \\
\hline 1957 & $\begin{array}{l}\text { Inilabas naman ang Carlos Palanca Awards for Literature, } \\
\text { English at Tagalog Prize-Winning Stories 1950-1955 ni } \\
\text { Kerima Polotan. }\end{array}$ \\
\hline 1965 & $\begin{array}{l}\text { Nalimbag ang unang edisyon ng } \underline{\text { Mga Agos sa Disyerto }} \\
\text { ng magkakaibigan at mga kabataang manunulat na unang } \\
\text { nagtagpo sa mga komersyal na magasin. }\end{array}$ \\
\hline
\end{tabular}

Ang imbensyong kanon ng mga kolonisador na Amerikano ay nagbunga ng kamalayang maglulugar sa pagiging nasa gilid ng panitikang Pilipino. Sinasagasaan nitong higit ang mga manunulat na piniling gamitin ang sariling wika upang itawid ang pag-unawa sa realidad na kanilang kinabibilangan. Higit na naging mapalad ang mga nagpaubaya upang maging duplikasyon ng mga Amerikano, bilang mga "gagad" sapagkat kahit papaano ay kinalinga sila ng kolonyal na estado. Pakikinabangan nila ang lahat ng maniobra ng mga kolonisador upang tuluyang kalimutan kundi man ikintal sa kamalayan ng mga Pilipino na ang lahat-lahat sa pagka-Pilipino ay segunda klase lamang. Naging kakambal ng kolonyal na kanong laging isinisik sa sistema ng edukasyon, ang komersyalismo sa disyerto ng panitikang Tagalog. Hanggang sa dalhin ng mga ito ang bayan sa pagkabaon sa lumang tradisyon sa panitikan na sumusupil/pumipigil sa pagsisikap na maiangat ng mga Pilipino ang sarili sa pamamagitan ng Panitikan. Sinubaybayan sa kabanatang ito ang sitwasyong ito at ang pagsisikap ng manunulat-Agos na buwagin ang gahum ng panitikang nakasulat sa Ingles sa paggiit ng antolohiyang nagbigkis sa mga manunulat na may di-na-kailangang-bigkasing-pamantayan ng "pagtinging paloob", paglalantad ng realidad at paggamit ng wikang Pilipino sa mga akdang kabilang sa antolohiyang Mga Agos sa Disyerto. 
Sa usapin ng pagtanggap ng mambabasang Pilipino sa isinakatuparan na "pagpapaagos sa disyerto" ng noo'y kabataang manunulat na pawang may maalab na hangarin ng pagbabago sa kalagayan ng panitikang Tagalog, unti-unting nabuwag ng kanilang antolohiya ang mababang pagkilala sa sariling panitikang nakasulat sa sariling wika ng bayan. Ang bilang ng edisyon ng aklat at ang natatanging pagkilala ng mga kritiko at edukador na karaniwang siyang humuhubog ng kanon ay patunay sa binasag na kalakaran/praktis ng kanon (na maka-Amerikano) at resepsyong positibo sa antolohiya. Sa ganang akin, ang lahat ng ito ay hindi lamang isang deskripsyon ng nagawa ng aklat at ng mga manunulat nito kundi pananalig sa kanilang politikal na posisyong naisatinig at pinanindigan sa pasya nilang ilabas ang Mga Agos sa Disyerto. 


\section{Notes}

1. Binigyang-kahulugan din ito bilang kalipunan ng mga gawang dakila ni John Guillory. Makikita sa Istratehiyang Ideyolohikal ng Kolonyalismong Amerikano sa Pilipinas: Pagsusuri ng Kanong Pampanitikan sa Paaralan, 1901-1942 ni Isabel Pefianco (di-limbag na disertasyon, Unibersidad ng Pilipinas, Diliman, Mayo 1999), p.18.

2. Bagaman, maraming iba pang timpalak ang nauna sa tanyag na Don Carlos Palanca Memorial Awards for Literature noong 1950, ito hanggang sa ngayon ang isa sa pinakaaabangan lalo na ng mga baguhang manunulat na nais magkaroon ng pangalan sa panitikan.

3. Jonathan Chua, The Critical Villa, p.27.

4. Sa kaso ng maikling kuwentong Pilipino, nagtago si Villa sa tinawag niyang laman (substance) at porma/anyo (form) na kinailangang matupad ng manunulat na hango niya mula sa mga natutuhan niya sa Estados Unidos.

5. Sa sariling pahayag ni Jonathan Chua: "Although he thought he was merely applying universal standards on the Filipino short story, he was, in a way, teaching Filipino writers to mimic their colonial master." Makikita sa The Critical Villa, p. 28.

6. Tinawag din itong rafaga-isang maikling anekdota o isang pangyayari. Sa unang dalawang dekada ng kolonisasyong Amerikano, itinumbas ang salitang sketches dito at tinawag ding dagli.

7. Teodoro A. Agoncillo, ed., "KAMI: Ang Maikling Kuwentong Tagalog Pasulyap na Tingin sa mga Tao at Kilusan" Ang Maikling Kuwentong Tagalog (1886-1948) (Manila: Inang Wika Publishing, 1978), p.13.

8. Mga akdang inihahandog sa mga paraluman gaya ng "Concha" ni Lope K. Santos, sang-ayon kay Teodoro A. Agoncillo at nasa Ang Maikling Kuwentong Tagalog (1886-1948), p.13-14.

9. Ayon naman kay Fausto J. Galauran, isang pagtatapat niya na kalimitan ay bukas na liham sa isang paraluman ang dagli. Nasa "Ang Maikling Kuento sa Panahon ng Amerikano at Komonwelt" ni Patricia Melendrez-Cruz sa Lagda, DFPP, UP Diliman, 1992, p.110.

10. Agoncillo, “Kami: Ang Maikling Kuwentong Tagalog,"p 14.

11. Ibid., p.16.

12. Melendrez-Cruz, "Ang Maikling Kuento sa Panahon ng Amerikano", p. 112-113.

13. Ang ginawang ito ni del Mundo ay katulad ng ginawa ni Jose Garcia Villa na naglabas naman ng tinawag nitong "Honor and Horror List".

14. Agoncillo, p. 21.

15. Melendrez-Cruz, p.12.

16. Agoncillo, p.23.

17. Pito ang itinalang katangiang matatagpuan sa panahon ng Panitikan at Ilaw ng Bayan para sa maikling kuwentong Tagalog na siya ring batayan ng pagtatasa. Ang mga ito ay ang paggamit ng unang panauhan; pagtalakay sa paksang nauukol sa buhay lungsod; katimpian sa pagpapahayag ng damdamin at paglalarawan; ang karaniwang kalabuan ng pangyayari sanhi ng pagpipilit na hindi maging 
lantad; pamamayani ng paghahangad na mapaganda ang kaanyuan; kadahupan sa malinis at tumpak na pananagalog; at pagsulat ng kuwentong nabibilang sa iba't ibang uri. Makikita ang nasabing pamantayan sa "Kami: Ang Maikling Kuwentong Tagalog" ni Teodoro Agoncillo nasa Ang Maikling Kuwentong Tagalog (1886-1948) ng pareho ring awtor, nilimbag noong 1978, nasa p.28.

18. Chua, p.123.

19. Terminong ginamit ni Agoncillo.

20. Agoncillo, p. 44-45.

21. Soledad S. Reyes, Nobelang Tagalog 1905-1975 Tradisyon at Modernismo (Quezon City: Ateneo de Manila University Press, 1982), p.159.

22. Chua, p.11.

23. Maihahakang ang lahat ng paratang na ito ay mauugat sa naging kasaysayan ng maikling kuwentong Tagalog kung saan nagsanib-sanib na ang oryentasyong isinilang mula sa dagli. Alalahaning ang malaking papel noon ng manunulat ay bilang tagapangaral. Samantala, popularidad at kita ang matutuntong dahilan sa patuloy na paggamit sa pormula na itinakda ng magasin para sa kanilang mga tagatangkilik.

24. Rogelio Sikat, "Ang Trahedya ng Manunulat sa Pilipino," The Varsitarian Tomo XXXVI Blg. 2 (Pebrero 1964), p.26.

25. Priscelina Patajo-Legasto, "Literatures from the Margins: Reterritorializing Philippine Literary Studies" Philippine Post-Colonial Studies:Essays on Language and Literature, ed. Cristina Pantoja Hidalgo at Priscelina Patajo-Legasto (Quezon City: DESCL, U.P at U.P. Press,1993), p.39.

26. Isabel Pefianco, "Istratehiyang Ideyolohikal ng Kolonyalismong Amerikano sa Pilipinas," p.2.

27. Ginamit na halimbawa dito ni Pefianco ang serye ng Ward's Readers, Baldwin's Readers, Bass's Readers, First Steps in Engish, Heart of Oak Series, Mother Tongue, Robinson Crusoe for Young Readers, Big People and Little People of Other Lands. Makikita sa pahina 130.

28. Ibid, p.135.

29. Ibid., p.136.

30. Ibid.

31. Mainam na banggitin na sa pag-aaral ni Pefianco, maging ang mga temang ito ay natunton niyang bahagi ng proyekto ng kolonisasyong Amerikano sapagkat aniya, ito ang mga karaniwang temang sinandigan ng mga babasahing Ingles na nagpapamalay sa mga mag-aaral sa unang apat na dekada ng kolonisasyong ito at nagbunga ng kultura ng pagtakas. Makikita sa disertasyon ni Pefianco sa p. 149-150.

32. Jose Duke Bagulaya, "The Utility of Literary Criticism: Pitfalls of the Literary Debates Under the US Colonial Regime" nasa Philippine Humanities Review vol. 9, ed. Ruth Jordana Pison at Galileo Zafra (Quezon City: CAL U.P., 2007) p. 69.

33. Ibid., p. 74 .

34. Sikat, "Ang Trahedya ng Manunulat na Pilipino", p.26.

35. Nasa Sila...Noon 9 na Manunulat sa Tagalog ang pahayag ni Agustin Fabian na naikuwento ni Liwayway Arceo sa interbyu sa kanya ni Efren R. Abueg, p. 109. 
36. Naikuwento ni Edgardo M. Reyes sa mananaliksik na gumamit ng pen name si Agustin Fabian noon na "Agusto C. Fuentes", pero aniya, siya rin ang sumusulat ng nobela. Iniatang din ni Fabian sa kaniya ang pag-eedit. Ani Reyes, ganito ang pahayag ni Fabian, "Basahin mo ang lahat ng chapter ng nobela nila. Lahat ng pintas mo, baguhin mo."

37. Nagmula ang datos sa May 1968 Bureau of Census and Statistical Labor Force survey na sinipi sa John J. Caroll at John Keene, "Philippine Social Condition and the Church," Solidarity, Oktubre 1970. Binanggit ni Soledad S. Reyes sa kanyang Nobelang Tagalog 1905-1975, Tradisyon at Modernismo (Quezon City: ADMU Press, 1982), p.155.

38. Pinatotohanan ito ni Dr. Jose Wendell Capili sa panayam ko sa kanya. Naibahagi ni Capili ang isang pangyayaring hindi lamang naging dahilan ng pagdaramdam umano ni Rogelio Sikat kundi naging patotoo rin sa higit na pagtangkilik ng UST sa panitikang Ingles at pagiging kolonyal nito. Aniya, nangyari ito sa paghahanda ng banquet ng UST para kay Rita Gaddi, manunulat sa Ingles na nagwagi ng Palanca; kasabay niyang nagwagi si Rogelio Sikat para sa kuwentong "Tata Selo", ngunit hindi siya kasamang pinarangalan. Nabanggit ito ni Sikat kay Capili.

39. Nasa direksyon ng adhikain ng mga nagtatag ng MLQU ang matimbang na pagtingin sa wika at panitikang Pilipino. Ayon nga kay Dr. Capili, sa kuwento ng kanyang ama na naging guro sina dating senador Jovito Salonga at Lorenzo Tanada (ang huli ang nagtayo ng MLQU), tinangkilik ng mga liberal at progresibong katulad nila ang pamumulaklak ng ganitong pag-iisip hindi lamang ng mga guro kundi maging ng mga estudyante sa MLQU.

40. Virgilio S. Almario, Balagtasismo Versus Modernismo: Panulaang Tagalog sa ika-2o Siglo, (Quezon City: Ateneo de Manila University Press, 1984), p.198.

41. Ibid., p.204-205.

42. Nasa The Quezonian, vol. 12, no. 10, Abril 2, 1960.

43. Bagulaya, "The Utility of Literary Criticism: Pitfalls of the Literary Debates under the US Colonial Regime", p.64.

44. Bagamat hindi kabilang sa mga manunulat na naglimbag ng Mga Agos sa Disyerto, si Ave Perez Jacob ang itinuturing ni Rogelio Sikat na nagturo ng makabagong kuwento sa Pilipino at pinakamabisang lider na sumalungat sa tradisyonal na panitikan at sa Liwayway. Kompirmasyon ang pahayag na ito sa naghaharing kalakaran/kondisyon ng panitikang Pilipino sa panahong iyon. Nabanggit ito ni Sikat sa isang limbag niyang journal entry sa Diario Uno, Agosto 4, 1998, p.5.

45. Efren Abueg et al., Talindaw: Kasaysayan ng Panitikan sa Pilipino para sa Kolehiyo at Unibersidad (Navotas: Regan Publishing, 1981), p.195.

46. Ibid.

47. Mula sa "Hindi Ngayon ang Panahon at iba pang Tala", na pangkalahatang pamagat ng journal ni Rogelio Sikat. May tiyak namang pamagat ang entry na "Kumusta sa Laya?" Ang manuskrito ng journal na ito ay ipinagkatiwala sa mananaliksik ni Luna Sicat-Cleto, anak ng yumaong Rogelio Sikat. Ang nabanggit na journal entry ay ngayon pa lamang mababasa. Hindi gaya ng iba pang journal entries ni Sikat, wala itong petsa kung kailan niya naisulat. 
48. Elmer A. Ordonez, Emergent Literature:Essays on Philippine Writing (Quezon City: University of the Philippines Press, 2001), p. 16.

49. Patricia Melendrez-Cruz, "The Modern Short Story (1946-1972): Consciousness and Counter-Consciousness" Panitikan at Kritisismo, ed. Rosario Torres-Yu (Caloocan: Philippine Graphic Arts, Inc., 1980), p.110.

50. Patuloy na inilayo ni Jose Garcia Villa ang pagbabad sa ubod/sentrong loob ng bayan sa paggigiit niya sa paniniwalang hindi maaaring iabandona ng isang tunay na artista ang kinalalagyan niyang toreng garing. Naging malaking pambulag ito sa mga manunulat na naniniwalang tiwalag sa anumang konteksto at higit na superyor ang sining sa anumang larangan. Upang maigiit ang paglayo sa ubod o sentrong loob ng bayan, nilinaw ni Villa na ang maaring pagsulat ng manunulat ukol sa inuunawa niyang tao at konteksto nito ay pagtupad sa pagiging tagapanood (spectator) lamang. Ito rin ang itataguyod ni Alejandro G. Abadilla nang ipinakikilala naman niya ang modernismo sa panulaang Tagalog. Makikita ang komentaryo ni Villa sa The Critical Villa, p. 227.

51. Rogelio Sikat, "Rebolusyon sa Panitikang Pilipino" Diario Uno (4 Agosto 1998), p.5. Bahagi ito ng mga journal ni Sikat na inilathala sa kolum na "Mga Alaala" ni Rogelio Sikat. Ito ang posthumous column na inilaan ni Edgardo M. Reyes (editor ng nasabing diyaryo noong panahong iyon) para sa yumaong kaibigan. Nabanggit ito ni Reyes sa interbyu ko sa kanya.

52. Nabanggit ito ni Rogelio Ordonez sa panayam sa kanya noong Mayo 2001.

53. Pawang nakatuntong sa kolehiyo ang grupong Agos. Naging malaking salik din ito sa mga "basahán" nila ng kani-kanilang mga akda. Kasama rin na napalulutang sa bahaginan nila ang kanilang kaalaman sa panitikan ng daigdig. (Si Edgardo M. Reyes lamang ang hindi nakakuha ng diploma sa kolehiyo.)

54. Panayam kay Edgardo M. Reyes noong ika-27 Agosto 2007.

55. Panayam kay Rogelio Ordonez noong Mayo 2001.

56. Sikat, "Rebolusyon sa Panitikang Pilipino", p.5.

57. Patajo-Legasto, "Literatures from the Margins: Reterritorializing Philippine Studies," p. 49.

58. Panayam kay Rogelio Ordonez.

59. Panayam kay Edgardo M. Reyes.

6o. Ibid.

61. Ibid., p.252.

62. Ibid., p.255.

63. Ibid.

64. Efren Abueg et al., Mga Agos sa Disyerto (Maynila: Limbagang Pilipino, 1965), p.vi.

65. Antonio G. Manuud, ed., Brown Heritage: Essays on Philippine Cultural Tradition and Literature (Quezon City: Ateneo de Manila University Press, 1967),p. 423.

66. Binanggit ni Bienvenido Lumbera ang interes na napukaw sa mambabasa sa $\mathrm{Mga}$ Agos sa Disyerto sa paglabas ng kanyang artikulo-rebyu dito sa Graphic Weekly. Nakapanghihinayang lamang na hindi na makita ng mag-aaral ang nasabing artikulo. Ang pahayag ay mababasa sa "Mga Agos sa Disyerto: The Agony and the Ecstacy of Writers in Pilipino" ni Melanie Manlogon, nasa National Midweek, Hulyo 26, 1989, p.12. 
67. Sa talaan ng nilalaman ng kanong inihanda ni Asuncion David-Maramba, mahalagang pansinin na kahit may pagtanggap na ito sa mga akdang nakasulat sa Pilipino, nakahihigit pa rin ang akda ng mga manunulat sa Ingles. Pitumpu't isa sa Ingles kumpara sa labimpitong akda sa Pilipino, kahit pa sa muling limbag noong 1993 ng edisyong 1990.

68. Sa panayam ko kay Rogelio Ordonez, pagkaraang maimprenta ang unang edisyon, sinabi niyang ipinagkatiwala na nila kay Efren Abueg ang pamamahala sa iba pang bagay gaya ng pagpapalimbag dito sa National Bookstore. Pagkaraan ng 1,500 kopya, hindi na nila nasubaybayan kung ilang kopya pa ang naipagawa.

69. Mula sa journal ni Rogelio Sikat na may pangkalahatang pamagat na "Hindi Ngayon ang Panahon at iba pang Tala". Binigyan ng tiyak na pamagat ang journal entry na "Ang Kaunting Matitira". Walang petsa.

\section{Works Cited}

Abueg, Efren, et al. Mga Agos sa Disyerto. Manila: Limbagang Pilipino. 1965. Print.

--. Talindaw: Kasaysayan ng Panitikan sa Pilipino para sa Kolehiyo at Unibersidad.

Navotas: Regan Publishing. 1981. Print.

Agoncillo, Teodoro, ed. "KAMI: Ang Maikling Kuwentong Tagalog Pasulyap na Tingin sa mga Tao at Kilusan." Ang Maikling Kuwentong Tagalog (1886-1948). Manila: Inang Wika Publishing. 1970. Print.

Almario, Virgilio S. Balagtasismo Versus Modernismo: Panulaang Tagalog sa ika-2o Siglo. Quezon City: Ateneo de Manila University Press. 1984. Print.

Bagulaya, Jose Duke. "The Utility of Literary Criticism: Pitfalls of the Literary Debates Under the US Colonial Regime." Philippine Humanities Review vol. 9. Eds. R. Pison and G. Zafra. Quezon City: CAL U.P. 2007. Print.

Chua, Jonathan. The Critical Villa, Essays in Literary Criticism by Jose Garcia Villa, Quezon City: Ateneo de Manila University Press. 2002. Print.

Manlogon, Melanie. "Mga Agos sa Disyerto: The Agony and the Ecstacy of Writers in Pilipino" in National Midweek. 1989. Print.

Manuud, Antonio G., ed. Brown Heritage: Essays on Philippine Cultural Tradition and Literature. Quezon City: Ateneo de Manila University Press. 1967. Print.

Melendrez-Cruz, P. "Ang Maikling Kuento sa Panahon ng Amerikano at Komonwelt." Lagda, DFPP, Quezon City University of the Philippines. 1992. Print.

--.. "The Modern Short Story (1946-1972): Consciousness and Counter-Consciousness." Panitikan at Kritisismo. Ed. R.T.Yu. Caloocan: Philippine Graphic Arts, Inc. 1980. Print.

Ordonez, Elmer A. Emergent Literature:Essays on Philippine Writing. Quezon City: University of the Philippines Press. 2001. Print.

Patajo-Legasto, Priscelina. "Literatures from the Margins: Reterritorializing Philippine Literary Studies." Philippine Post-Colonial Studies:Essays on Language and Literature. Eds. C.P.Hidalgo and P. Patajo-Legasto. Quezon City: DESCL, U.P and U.P. Press. 1993. Print. 
Pefianco, Isabel. Istratehiyang Ideyolohikal ng Kolonyalismong Amerikano sa Pilipinas: Pagsusuri ng Kanong Pampanitikan sa Paaralan, 1901-194.2 unpublished dissertation. Quezon City: University of the Philippines. 1999. Print.

Reyes, Soledad S. 1982. Nobelang Tagalog 1905-1975 Tradisyon at Modernismo. Quezon City: Ateneo de Manila University Press. 1982. Print.

Sikat, Rogelio. "Ang Trahedya ng Manunulat sa Pilipino," The Varsitarian Volume XXXVI No. 2, Manila: University of Sto. Tomas. 1964. Print.

--. "Hindi Ngayon ang Panahon at iba pang Tala" unpublished journal.

--. "Rebolusyon sa Panitikang Pilipino." Diario Uno. 1998. Print. 